\title{
Evaluation of uncertainties due to hydrogeological modeling and groundwater flow analysis: steady flow, transient flow, and thermal studies
}

\author{
Christine Doughty and Kenzi Karasaki \\ Earth Sciences Division \\ Lawrence Berkeley National Laboratory
}

December 2002

\begin{abstract}
Starting with regional geographic, geologic, surface and subsurface hydrologic, and geophysical data for the Tono area in Gifu, Japan, we develop an effective continuum model to simulate subsurface flow and transport in a $4 \mathrm{~km}$ by $6 \mathrm{~km}$ by $3 \mathrm{~km}$ thick fractured granite rock mass overlain by sedimentary layers. Individual fractures are not modeled explicitly. Rather, continuum permeability and porosity distributions are assigned stochastically, based on well-test data and fracture density measurements. Lithologic layering and one major fault, the Tsukiyoshi Fault, are assigned deterministically. We conduct three different studies: (1) the so-called base case, in which the model simulates the steady-state groundwater flow through the site, and then stream trace analysis is used to calculate travel times to the model boundary from specified release points; (2) simulations of transient flow during long term pump tests (LTPT) using the base-case model; and (3) thermal studies in which coupled heat flow and fluid flow are modeled, to examine the effects of the geothermal gradient on groundwater flow. The base-case study indicates that the choice of open or closed lateral boundaries has a strong influence on the regional groundwater flow patterns produced by the models, but no field data exist that can be used to determine which boundary conditions are more realistic. The LTPT study cannot be used to distinguish between the alternative boundary conditions, because the pumping rate is too small to produce an analyzable pressure response at the model boundaries. In contrast, the thermal study shows that the temperature distributions produced by the open and closed models differ greatly. Comparison with borehole temperature data may be used to eliminate the closed model from further consideration.
\end{abstract}

\section{Introduction}

The Japan Nuclear Cycle Development Institute (JNC) has initiated a multi-national project to investigate the uncertainties involved in the prediction of flow and transport behavior of a fractured rock mass. In the initial stage of the project, known as the CORE Collaborative Study (Oyamada and Ikeda, 1999; Doughty and Karasaki, 1999), several research organizations conducted numerical simulations of tracer transport through a hypothetical fractured rock mass at the $100 \mathrm{~m}$ scale. Each group was provided with the same hydrogeological data set and was requested to use the same boundary conditions. The groups' results were compared to identify and quantify uncertainties in model predictions. The study found that discrete fracture network (DFN) models and effective continuum models (ECM) produced comparable results for mean 
values of flow through the model and tracer travel times, but that DFN models showed greater variability among stochastic realizations than did ECM.

The second stage of the project took a similar approach, but provides site-characterization data for a real field site, a $4 \mathrm{~km}$ by $6 \mathrm{~km}$ by $3 \mathrm{~km}$ region surrounding the MIU site in the Tono area of Gifu, Japan, and left the choice of boundary conditions up to the research groups. The main results of the different groups' models were the predicted travel times from specified release points to the model boundary. There are no comparable field data available to directly validate the models, so, as in the first stage, model uncertainty was assessed by comparing among results of different models (Sawada et al, 2001). Although the general features of the flow paths from the release points to the model boundaries were similar for all the models, travel times varied over a huge range - from 1 to 10,000,000 years. Much of this variation could be attributed to the large range of fracture porosities assumed by the different groups, but direct comparison between models was difficult because of differences in how boundary conditions were assigned.

The present report describes additional modeling of the region surrounding the MIU site. In this stage, JNC specified a set of common boundary conditions for all the groups to use, so that differences in results could be related directly to the modeling approach and property assignments. The study comprises three parts: steady-flow and stream-trace-transport analysis (as was done previously), transient-flow analysis by simulating the Long-Term Pump Test (LTPT), and thermal analysis of steady-flow conditions. Comparison of the results of our isothermal studies with those of the other research groups is presented in Sawada et al. (2003). We were the only group to conduct thermal studies.

\section{Summary of Previous Studies}

Starting with regional geographic, geologic, surface and subsurface hydrologic, and geophysical data, we developed an effective continuum model to simulate subsurface flow and transport in a $4 \mathrm{~km}$ by $6 \mathrm{~km}$ by $3 \mathrm{~km}$ thick fractured granite rock mass overlain by about $100 \mathrm{~m}$ of sedimentary rock. Individual fractures were not modeled explicitly. Rather, continuum permeability and porosity values were assigned to the $100 \mathrm{~m}$ by $100 \mathrm{~m}$ by $100 \mathrm{~m}$ grid blocks stochastically, based on hydraulic conductivities determined from well-test data and fracture density measurements. Large-scale features such as lithologic layering and several fault zones were assigned deterministically. The top of the model coincides with the ground surface, with topographic relief determined from a $20 \mathrm{~m}$ by $20 \mathrm{~m}$ resolution digital terrain map (Figure 2.1). Near the top of the model, grid block thickness decreases to $50 \mathrm{~m}$ to better resolve surface topography. In the bottom third of the model, where no property data is available, it gradually increases.

\subsection{Stochastic permeability and porosity distributions}

The field data from which model permeabilities and porosities were derived consists of 283 hydraulic conductivity $(K)$ values, inferred from slug tests and pumping tests using packed-off intervals in 14 boreholes, and 67 fracture density $(d)$ measurements made from borehole imaging and core analysis in 5 boreholes. We did not interpret the $K$ values as representing individual fracture conductivities, but as representing effective continuum conductivities averaged over the 
length of the packed-off interval. Because we chose grid block size to be comparable to typical lengths of packed-off intervals, we assumed that there was no need to scale up or scale down $K$ values measured during well tests, and that they directly represented the effective continuum conductivities required for the model.

Grid block conductivity values were drawn from stochastic distributions for each lithologic layer (i.e., each material type in the model). For the granitic rocks, the distributions were constructed by resampling field measurements. For the sedimentary rocks, there were not enough measurements for a given material type to make resampling viable, so log-normal distributions were used. Table 2.1 summarizes the material types and conductivity distributions used for the model and Figure 2.2 illustrates the $\log _{10} K$ distributions that were constructed by resampling. To investigate whether the $K$ distributions showed a spatial correlation structure between the grid block scale $(100 \mathrm{~m})$ and the lithofacies scale $(\sim 800 \mathrm{~m})$, we created $K$ versus depth profiles for individual wells, and then we compared these profiles among various wells. Results suggested that $K$ is not strongly spatially correlated at this scale, so field measurements within each material type were randomly shuffled before being assigned to grid blocks. Permeability is simply the product of $K$ and the ratio of water viscosity $\mu$ to specific gravity $\rho g$, which is a constant for an isothermal system.

Counting fractures observed in borehole images enables fracture density $d$ (number of fractures per meter) to be estimated. We assume that fracture spacing $b$ is inversely related to fracture density

$$
b=1 / d .
$$

Porosity $\phi$ is estimated as the ratio of fracture aperture $w$ to fracture spacing $b$

$$
\phi=w / b .
$$

The relationship between $w$ and $K_{f}$, the individual fracture conductivity, is obtained from the parallel-plate assumption for fracture flow (National Research Council Committee on Fracture Characterization and Fluid Flow, 1996).

$$
w^{2} /(12 \mu)=K_{f} .
$$

Since the effective continuum conductivity $K$ is related to $K_{f}$ according to

$$
K=K_{f}(w / b),
$$

we get the well-known cubic law relating $w$ and $K$

$$
K=w^{3} /(12 \mu b) .
$$

We combine Equations (2.1), (2.2), and (2.5) to write $\phi$ in terms of $K$ and $d$

$$
\phi=\left(12 K \mu d^{2}\right)^{1 / 3} .
$$


Fracture density measurements are sparse and we could find no obvious correlation between $d$ and $K$, so $d$ measurements from all lithological layers were combined to determine a mean fracture density of $7.95 \mathrm{~m}^{-1}$ and a standard deviation of $5 \mathrm{~m}^{-1}$. For most of the lithological layers, $d$ values were drawn from a normal distribution with these moments, which is truncated at a small positive number $\left(0.01 \mathrm{~m}^{-1}\right)$ to ensure that $d$ is always positive. However, for the biotiterich and felsic granites, $d$ distributions were created by resampling.

For each grid block, after $K$ and $d$ had been drawn from the appropriate distribution, Equation (2.6) was applied to determine $\phi$. The resulting model porosity statistics are summarized in Table 2.1. Note that $\phi$ is always positive, but the standard deviation is typically the same magnitude as the mean, implying that the $\phi$ distribution is distinctly non-normal.

Table 2.1. Summary of material properties used in the model. For sedimentary rocks with no data available, typical stochastic properties are used. For deep granitic layers, the mean $K$ of each layer is three times smaller than that of the overlying layer.

\begin{tabular}{|c|c|c|c|c|c|}
\hline \multirow[b]{2}{*}{ Material Type } & \multirow{2}{*}{$\begin{array}{c}\text { Number of } \\
\text { conductivity } \\
\text { measurements }\end{array}$} & \multicolumn{2}{|c|}{$\log _{10} K(\mathrm{~m} / \mathrm{s})$} & \multirow{2}{*}{\multicolumn{2}{|c|}{$\begin{array}{l}\text { Type of distribution } \\
\text { used for } \log _{10} K\end{array}$}} \\
\hline & & Mean & Std. Dev. & & \\
\hline Alluvium & \begin{tabular}{|l|}
0 \\
\end{tabular} & -7.9 & 1.6 & \multicolumn{2}{|c|}{ Normal } \\
\hline Seto group & 0 & -7.9 & 1.6 & \multicolumn{2}{|c|}{ Normal } \\
\hline Oidawara & 1 & -8.7 & 1.6 & \multicolumn{2}{|c|}{ Normal } \\
\hline Akeyo & 11 & -7.9 & 0.8 & \multicolumn{2}{|c|}{ Normal } \\
\hline $\begin{array}{l}\text { Toki lignite- } \\
\text { bearing }\end{array}$ & 21 & -7.0 & 0.9 & \multicolumn{2}{|c|}{ Normal } \\
\hline $\begin{array}{l}\text { Toki granite } \\
\text { (biotite) }\end{array}$ & 192 & -7.1 & 1.7 & \multicolumn{2}{|c|}{ Resampled } \\
\hline $\begin{array}{l}\text { Toki granite } \\
\text { (felsic) }\end{array}$ & 46 & -6.9 & 1.1 & \multicolumn{2}{|c|}{ Resampled } \\
\hline $\begin{array}{l}\text { Deep granitic } \\
\text { layers }\end{array}$ & 0 & -8.0 to -8.9 & 1.6 & \multicolumn{2}{|c|}{ Normal } \\
\hline Faults & 12 & -7.7 & 1.0 & \multicolumn{2}{|c|}{$\begin{array}{l}\text { Tsukiyoshi resampled; } \\
\text { others normal }\end{array}$} \\
\hline $\begin{array}{c}\text { Average over all } \\
\text { rock types }\end{array}$ & 283 & -7.3 & 1.5 & & \\
\hline \multirow[b]{2}{*}{ Material Type } & \multirow{2}{*}{\begin{tabular}{|c|} 
Number of \\
fracture \\
density \\
measurements
\end{tabular}} & \multicolumn{2}{|c|}{ Fracture density $\left(\mathrm{m}^{-1}\right)$} & \multicolumn{2}{|c|}{ Model Porosity } \\
\hline & & Mean & Std. Dev. & Mean & Std. Dev. \\
\hline $\begin{array}{l}\text { Toki granite } \\
\text { (biotite) }\end{array}$ & Fom & 7.7 & 4.2 & $3.9 \mathrm{E}-4$ & $5.9 \mathrm{E}-4$ \\
\hline $\begin{array}{c}\text { Toki granite } \\
\text { (felsic) }\end{array}$ & 4 & 10.8 & 4.2 & $3.5 \mathrm{E}-4$ & $2.7 \mathrm{E}-4$ \\
\hline $\begin{array}{c}\text { Average over all } \\
\text { rock types }\end{array}$ & 67 & 7.9 & 5.0 & $3.2 \mathrm{E}-4$ & $4.2 \mathrm{E}-4$ \\
\hline
\end{tabular}


Model porosity is considered to be less well constrained than model conductivity for several reasons. First, basing porosity estimates on fracture density measurements is problematic because often a high percentage of observed fractures do not contribute to flow at all (National Research Council Committee on Fracture Characterization and Fluid Flow, 1996). Moreover, the cubic law can greatly misrepresent the relationship between fracture aperture and conductivity, and even if it is valid, the hydraulic aperture used in the cubic law tends to underestimate the volumetric aperture relevant for transport. Finally, there are few fracture density measurements available for materials other than the biotite-rich granite. Note that no data whatsoever are available for depths below $1000 \mathrm{~m}$. Hence, all model properties there are quite uncertain.

\subsection{Boundary conditions}

The top boundary of the model is a constant-head boundary, with the head value set equal to the ground surface elevation (that is, the water table is coincident with the ground surface, eliminating consideration of the vadose zone). With such a boundary condition, water flows into or out of the model according to local head differences. Water flowing in is interpreted as infiltration or recharge whereas water flowing out is interpreted as spring discharge or the conversion of groundwater to surface water in rivers and creeks. The bottom boundary of the model is closed. Moreover, the mean permeability of the lowest three layers of the model gradually decreases, to represent the closing of fractures with increased lithologic stress, and to provide a gradual transition to the closed boundary. Where the lateral boundaries of the model coincide with ridgelines or other natural groundwater divides, the boundary is closed to represent a line of symmetry across which water is not expected to flow (Figure 2.1). Constant head boundaries apply in two places where rivers intersect the model boundary: the entire southern boundary of the model, which is coincident with a stretch of the Toki River, and over a short low-elevation section along the NE boundary of the model, where the Hiyoshi River flows. The constant head value, equal to the ground surface elevation, applies over the uppermost 16 layers of the model, below which all lateral boundaries are closed. Because of variations in the top elevation of the model and differences in grid layer thicknesses, the uppermost 16 layers of the model extend to about -800 masl for the Hiyoshi River open boundary, and to about -1700 masl for the Toki River open boundary

\subsection{Calculation procedure}

Ten stochastic realizations of the model were generated. We employed the TOUGH2 simulator (Pruess et al., 1999) to calculate the steady-state groundwater flow through the model, then used the graphics package Tecplot to calculate stream traces from 24 specified release points to the model boundaries, based on the TOUGH2 flow field. Model results for the head distribution compared favorably with head profiles measured in several deep boreholes and the overall groundwater flow was consistent with regional water budget data that suggests surface recharge

rate is on the order of 100 to $200 \mathrm{~mm} / \mathrm{yr}$. Predicted travel times ranged from 1 to 25 years. Further details may be found in Doughty and Karasaki (2001). 


\section{New Base Case}

Whereas our previous model had mostly closed lateral boundaries, the new base case specifications call for open (constant-head) lateral boundaries, except under the Toki River at the southern boundary of the model (Figure 2.1). The top layer of the model at the Toki River is a constant head boundary, but all the underlying layers are closed. At all open boundaries, head is set equal to ground surface elevation, although JNC's problem specifications call for a head of ground surface elevation minus five meters. For a saturated system, flow is sensitive only to head differences, not to the head values themselves, so this choice does not impact the simulated flow field. Using a higher head value does ensure that the system will remain single-phase liquid rather than making a transition to two-phase (unsaturated) conditions. TOUGH2 is capable of handling two-phase conditions, but the nonlinear calculations involved would increase computation time significantly. For the present problem, not enough is known about the vadose zone conditions to make it worthwhile to expend the additional computational effort to model it.

Another significant difference from the previous model is in the treatment of the Tsukiyoshi Fault, a major east-west sub-vertical fault that passes through the center of the model. In the previous model, fault grid blocks either used essentially the same conductivity distribution as other granitic materials or, in an alternative scenario, used a distribution with a ten times lower mean conductivity. In the new base case, the fault is treated more elaborately, with a lowconductivity plane surrounded by high-conductivity planes on either side (Figure 3.1). The lowconductivity plane has a mean conductivity ten times lower than the bulk fractured rock (based on field data), and the high-conductivity planes have a mean conductivity ten times higher than the bulk fractured rock (no quantitative data available, but well-test observations by Takeuchi et al. (2001) suggest a high conductivity zone adjacent to the fault). All three fault planes use lognormal distributions from which to draw hydraulic conductivities. No other faults are included in the new model.

There are no porosity or fracture density measurements for any of the sedimentary materials. In the previous model, these materials were assigned porosities in the same way that the granitic rocks were, using observed values of hydraulic conductivity and fracture density in the cubic law, which probably yielded unrealistically low values (mean granite porosities are on the order of $410^{-4}$ in each realization). The new base cases use a mean porosity of 0.2 for all sedimentary materials, a typical value taken from the literature.

The Tono mine, which was specified as a constant mass sink in the previous model, is not included in the new base case. The average flow rate out of the mine $(0.57 \mathrm{~kg} / \mathrm{sec})$ is quite small compared to the other components of the water budget (see below), so the presence or absence of the mine is not expected to have much impact.

To enable the effects of the new open lateral boundary conditions to be assessed, a variation on the new base case is also developed, which retains the new treatment of the Tsukiyoshi fault and sedimentary rock porosity, but returns to the mostly closed lateral boundary conditions of the previous model. We call this variation the closed model, in comparison to the new base case itself, which is called the open model. Five stochastic realizations are created of each model. 


\section{Steady State Flow and Transport}

\subsection{Water budget and boundary flows}

Table 4.1 summarizes the water budgets for the open and closed versions of the new base case. For the open model, water enters along the east, north, and west sides of the model and mainly exits the model through the surface. For the closed model, water infiltrates through the surface, moves down through the model, and mainly exits at the southern Toki River boundary.

Table 4.1. Water budgets for five realizations of the open and closed versions of the new base case. Flow rates $(\mathrm{kg} / \mathrm{s})$ into the model are positive.

\begin{tabular}{|l|l|l|l|l|}
\hline $\begin{array}{l}\text { Open } \\
\text { Model }\end{array}$ & Surface & $\begin{array}{l}\text { Toki } \\
\text { River }\end{array}$ & $\begin{array}{l}\text { North } \\
\text { Side }\end{array}$ & $\begin{array}{l}\text { East and } \\
\text { West Sides }\end{array}$ \\
\hline C001 & -119 & -7 & 26 & 100 \\
\hline C002 & -100 & -4 & 29 & 75 \\
\hline C003 & -123 & -5 & 33 & 95 \\
\hline C004 & -67 & -5 & 28 & 44 \\
\hline C005 & -86 & -3 & 20 & 69 \\
\hline Average & $-\mathbf{9 9}$ & $\mathbf{- 5}$ & $\mathbf{2 7}$ & $\mathbf{7 7}$ \\
\hline $\begin{array}{l}\text { Closed } \\
\text { Model }\end{array}$ & Surface & $\begin{array}{l}\text { Toki } \\
\text { River }\end{array}$ & $\begin{array}{l}\text { Hiyoshi } \\
\text { River }\end{array}$ & \\
\hline J001 & 65 & -57 & -8 & \\
\hline J002 & 63 & -55 & -8 & \\
\hline J003 & 61 & -53 & -8 & \\
\hline J004 & 65 & -57 & -8 & \\
\hline J005 & 62 & -55 & -7 & \\
\hline Average & $\mathbf{6 3}$ & $\mathbf{- 5 5}$ & $\mathbf{- 8}$ & \\
\hline
\end{tabular}

Figure 4.1 shows the spatial flow distribution across the lateral boundaries for one of the open model realizations. Inflow and outflow are interspersed across the lateral boundaries, but the net inflow through the lateral boundaries is significant, as shown in Table 4.1.

Figures 4.2 and 4.3 show the distribution of flow through the top surface for the same realization of the open and closed models. There are both upward and downward flows through the top surface boundary for both models and the spatial flow distributions are similar for the two models, being generally controlled by surface topography. However, given the additional lateral inflow present in the open model, surface inflows tend to be smaller and surface outflows tend to be larger compared to the closed model. This effect is so strong that the net surface flow is in the opposite direction for the open and closed models.

Observed surface recharge data is only available for a small fraction of the $4 \mathrm{~km}$ by $6 \mathrm{~km}$ model. This data shows recharge into the model most years, with an average value in the range of 100 to $200 \mathrm{~mm} / \mathrm{yr}$. The closed model average recharge rate of $63 \mathrm{~kg} / \mathrm{s}$ corresponds to $106 \mathrm{~mm} / \mathrm{yr}$, which certainly appears more consistent with the field data than the open model, which shows discharge rather than recharge. However, observed water budget data comparing precipitation, stream flow, and recharge may relate primarily to shallow subsurface flow that is localized in the 
sedimentary rocks overlying the granitic basement. The model's coarse vertical discretization near the surface $(50 \mathrm{~m})$ makes it difficult to accurately model such flows. Therefore, we cannot eliminate the open model from consideration solely based on its worse prediction of surface recharge data.

\subsection{Stream traces from release points}

The stream traces leaving the 24 release points follow markedly different vertical routes for the two models (Figures 4.4 and 4.5). In the open model, most of the stream traces exit the model through the surface north of the Toki River. In the closed model, most of the stream traces reach the southern Toki River boundary. It is apparent that the choice of lateral boundary conditions has a large effect on the steady-state flow fields.

Note in Figures 4.2 and 4.3 that many of the biggest surface flows are in the vicinity of the Tsukiyoshi fault. These large flows arise because the combination of regional groundwater flow from north to south and the low-permeability sub-vertical fault plane creates vertical pressure gradients in the vicinity of the fault. Then, the high-permeability 'sandwich' planes surrounding the fault enable large flows to be driven by these gradients.

Tables 4.2 and 4.3 tabulate information for each stream trace for one realization of the open and closed models, respectively. Entries include stream trace starting location $\left(\mathrm{x}_{0}, \mathrm{y}_{0}, \mathrm{z}_{0}\right)$, ending location $\left(\mathrm{x}_{\mathrm{f}}, \mathrm{y}_{\mathrm{f}}, \mathrm{z}_{\mathrm{f}}\right)$, mean $\log$ hydraulic conductivity $\left(\log _{10} \mathrm{~K}\right)$, mean porosity $(\phi)$, path length $(\mathrm{L})$, travel time (t), and velocity (v). Figures 4.6 and 4.7 show travel time and path length graphically for all realizations, and Table 4.4 summarizes the mean performance measures. Average travel time from release points to model boundary decreases from 8 years for the closed model to 3.3 years for the open model. This decrease is partly due to the shorter flow paths present in the open model (average length $1836 \mathrm{~m}$ compared to $3010 \mathrm{~m}$ in the closed model). However, the average velocity along the flow paths is also significantly higher for the open model $(557 \mathrm{~m} / \mathrm{yr})$ than for the closed model $(381 \mathrm{~m} / \mathrm{yr})$. This velocity difference reflects the higher average conductivity encountered along the shallower flow paths of the open model.

Note in Tables 4.2 and 4.3 that most of the stream traces show average porosities on the order of $5 \cdot 10^{-4}$, which indicates that these flow paths remain largely in granitic rocks. Just four stream traces for the open model and two stream traces for the closed model show higher average porosities, indicating a notable contribution from travel through sedimentary rocks. However, when the average porosity is calculated for all the stream traces (Table 4.4), these large porosities dominate the averages, producing misleading results. A sensitivity study in which sedimentary rocks were assigned the low porosities typical of granitic rocks yielded almost no difference in travel times. As represented in the present models, the sedimentary layers are not widespread enough to significantly impact travel time. This is partly due to the coarse grid discretization used (100 by $100 \mathrm{~m}$ lateral spacing and $50 \mathrm{~m}$ vertical extent for depths where sedimentary rocks may be found), which ignores any sedimentary body less than $50 \mathrm{~m}$ thick. In fact, since the release points are all in granitic rock, the use of upstream weighting at grid block interfaces effectively means that any sedimentary body less than two grid blocks thick $(100 \mathrm{~m})$ will be ignored. 
Table 4.2. Stream trace summary for open model C001.

\begin{tabular}{|c|c|c|c|c|c|c|c|c|c|c|}
\hline $\begin{array}{l}\mathbf{x}_{0} \\
(\mathbf{m})\end{array}$ & $\begin{array}{l}y_{0} \\
\text { (m) }\end{array}$ & $\begin{array}{l}z_{0} \\
(m)\end{array}$ & $\begin{array}{l}\log _{10} K \\
(K \text { in } \\
m / s)\end{array}$ & $\phi$ & $\begin{array}{l}\text { L } \\
\text { (m) }\end{array}$ & $\begin{array}{l}t \\
(y r)\end{array}$ & $\begin{array}{l}\mathbf{x}_{\mathrm{f}} \\
(\mathrm{m})\end{array}$ & $\begin{array}{l}y_{f} \\
(m)\end{array}$ & $\begin{array}{l}z_{\mathrm{f}} \\
(\mathrm{m})\end{array}$ & $\begin{array}{l}\mathbf{v} \\
(\mathbf{m} / \mathbf{y r})\end{array}$ \\
\hline 4489 & -66900 & -250 & -5.5 & $4.0 \mathrm{E}-04$ & 2432 & 8.1 & 5280 & -68249 & 264 & 300 \\
\hline 4489 & -66900 & -500 & -5.4 & $4.8 \mathrm{E}-04$ & 2386 & 7.7 & 5275 & -68246 & 276 & 311 \\
\hline 4489 & -66900 & -750 & -5.9 & 4.4E-04 & 3376 & 7.1 & 5861 & -69171 & 186 & 473 \\
\hline 4489 & -66900 & -1000 & -5.7 & 5.6E-04 & 3462 & 7.4 & 5644 & -69160 & 194 & 465 \\
\hline 5489 & -66900 & -250 & -5.4 & $4.0 \mathrm{E}-04$ & 1021 & 3.4 & 5839 & -67277 & 273 & 299 \\
\hline 5489 & -66900 & -500 & -5.5 & $4.8 \mathrm{E}-04$ & 2038 & 3.8 & 6434 & -67816 & 260 & 541 \\
\hline 5489 & -66900 & -750 & -5.3 & $5.2 \mathrm{E}-04$ & 2380 & 6.5 & 6455 & -67995 & 250 & 366 \\
\hline 5489 & -66900 & -1000 & -5.8 & $4.2 \mathrm{E}-04$ & 2409 & 6.8 & 6435 & -67998 & 254 & 354 \\
\hline 6489 & -66900 & -250 & -5.4 & $3.0 \mathrm{E}-04$ & 880 & 2.2 & 7155 & -66641 & -61 & 410 \\
\hline 6489 & -66900 & -500 & -5.2 & $5.7 \mathrm{E}-04$ & 889 & 1.5 & 7165 & -66632 & -125 & 608 \\
\hline 6489 & -66900 & -750 & -5.7 & 4.6E-04 & 924 & 1.0 & 7236 & -66732 & -817 & 921 \\
\hline 6489 & -66900 & -1000 & -6.0 & $4.5 \mathrm{E}-04$ & 999 & 2.3 & 7256 & -66725 & -892 & 438 \\
\hline 4489 & -68629 & -250 & -5.2 & $6.0 \mathrm{E}-04$ & 894 & 0.4 & 4437 & -68604 & 254 & 2205 \\
\hline 4489 & -68629 & -500 & -6.0 & $3.9 \mathrm{E}-04$ & 3059 & 5.1 & 5213 & -70646 & 159 & 603 \\
\hline 4489 & -68629 & -750 & -6.0 & $3.8 \mathrm{E}-04$ & 3022 & 4.7 & 5222 & -70649 & 155 & 643 \\
\hline 4489 & -68629 & -1000 & $\begin{array}{l}-5.9 \\
\end{array}$ & $4.9 \mathrm{E}-04$ & 2855 & 3.4 & 5127 & -70622 & 179 & 842 \\
\hline 5489 & -68629 & -250 & $\begin{array}{l}-5.3 \\
\end{array}$ & $5.8 \mathrm{E}-04$ & 924 & 0.8 & 5873 & -69205 & 187 & 1103 \\
\hline 5489 & -68629 & -500 & -5.7 & $4.5 \mathrm{E}-04$ & 1221 & 0.8 & 5777 & -69224 & 209 & 1525 \\
\hline 5489 & -68629 & -750 & $\begin{array}{l}-5.9 \\
\end{array}$ & $5.0 \mathrm{E}-04$ & 2041 & 3.4 & 5854 & -69822 & 192 & 608 \\
\hline 5489 & -68629 & -1000 & -6.2 & $4.1 \mathrm{E}-04$ & 2533 & 5.6 & 5460 & -70510 & 172 & 452 \\
\hline 6489 & -68629 & -250 & -6.0 & $2.4 \mathrm{E}-02$ & 475 & 0.3 & 6480 & -68723 & 202 & 1758 \\
\hline 6489 & -68629 & -500 & $\begin{array}{l}-5.1 \\
\end{array}$ & 7.4E-03 & 826 & 0.8 & 6329 & -68796 & 207 & 1102 \\
\hline 6489 & -68629 & -750 & $\begin{array}{l}-5.1 \\
\end{array}$ & $2.4 \mathrm{E}-03$ & 1250 & 1.1 & 6290 & -68807 & 206 & 1165 \\
\hline 6489 & -68629 & -1000 & -6.0 & $1.9 \mathrm{E}-03$ & 2982 & 4.2 & 6350 & -70827 & 168 & 705 \\
\hline Avg & & & -5.6 & $1.9 \mathrm{E}-03$ & 1887 & 3.7 & & & & 513 \\
\hline
\end{tabular}


Table 4.3. Stream trace summary for closed model J001.

\begin{tabular}{|c|c|c|c|c|c|c|c|c|c|c|}
\hline $\begin{array}{l}\mathbf{x}_{0} \\
(\mathbf{m})\end{array}$ & $\begin{array}{l}\mathbf{y}_{0} \\
(\mathbf{m})\end{array}$ & $\begin{array}{l}\mathbf{z}_{0} \\
(\mathbf{m})\end{array}$ & $\begin{array}{l}\log _{10} K \\
(K \text { in } \\
\mathrm{m} / \mathrm{s})\end{array}$ & $\phi$ & $\begin{array}{l}\mathbf{L} \\
(\mathrm{m})\end{array}$ & $\begin{array}{l}\text { t } \\
(y r)\end{array}$ & $\begin{array}{l}\mathbf{x}_{\mathbf{f}} \\
(\mathbf{m})\end{array}$ & $\begin{array}{l}\mathbf{y}_{\mathbf{f}} \\
(\mathbf{m})\end{array}$ & $\begin{array}{l}\mathbf{z}_{\mathrm{f}} \\
(\mathrm{m})\end{array}$ & $\begin{array}{l}\mathbf{v} \\
(\mathrm{m} / \mathrm{yr})\end{array}$ \\
\hline 4489 & -66900 & -250 & -5.9 & 4.7E-04 & 4941 & 12.4 & 5221 & -70654 & -1114 & 398 \\
\hline 4489 & -66900 & -500 & -5.9 & $4.4 \mathrm{E}-04$ & 4594 & 13.2 & 5078 & -70669 & -967 & 348 \\
\hline 4489 & -66900 & -750 & -5.9 & $4.3 \mathrm{E}-04$ & 4555 & 12.5 & 5189 & -70664 & -1154 & 364 \\
\hline 4489 & -66900 & -1000 & -5.8 & $3.7 \mathrm{E}-04$ & 4825 & 13.5 & 5243 & -70661 & -1368 & 358 \\
\hline 5489 & -66900 & -250 & -5.5 & $4.0 \mathrm{E}-04$ & 1902 & 15.1 & 6455 & -68000 & 245 & 126 \\
\hline 5489 & -66900 & -500 & -5.9 & $4.3 \mathrm{E}-04$ & 5124 & 12.4 & 6156 & -71163 & -617 & 412 \\
\hline 5489 & -66900 & -750 & -6.1 & $4.1 \mathrm{E}-04$ & 4897 & 16.5 & 6105 & -71156 & -738 & 297 \\
\hline 5489 & -66900 & -1000 & -5.8 & $4.2 \mathrm{E}-04$ & 3179 & 13.0 & 6257 & -68626 & -2724 & 244 \\
\hline 6489 & -66900 & -250 & -5.4 & $6.4 \mathrm{E}-04$ & 1042 & 2.8 & 7291 & -66732 & -284 & 376 \\
\hline 6489 & -66900 & -500 & -5.4 & $5.0 \mathrm{E}-04$ & 1077 & 4.2 & 7231 & -66744 & -831 & 259 \\
\hline 6489 & -66900 & -750 & -5.6 & $5.3 \mathrm{E}-04$ & 947 & 1.7 & 7236 & -66735 & -869 & 543 \\
\hline 6489 & -66900 & -1000 & -6.0 & $3.9 \mathrm{E}-04$ & 5091 & 29.6 & 6911 & -70862 & -1365 & 172 \\
\hline 4489 & -68629 & -250 & -5.6 & $5.1 \mathrm{E}-04$ & 2661 & 2.5 & 5080 & -70672 & -882 & 1063 \\
\hline 4489 & -68629 & -500 & -5.8 & $4.5 \mathrm{E}-04$ & 2441 & 3.0 & 5080 & -70676 & -880 & 818 \\
\hline 4489 & -68629 & -750 & -5.9 & $4.2 \mathrm{E}-04$ & 2305 & 2.1 & 5079 & -70669 & -884 & 1115 \\
\hline 4489 & -68629 & -1000 & -5.9 & 4.7E-04 & 2439 & 2.9 & 5081 & -70678 & -990 & 854 \\
\hline 5489 & -68629 & -250 & -6.1 & $3.8 \mathrm{E}-04$ & 2546 & 3.6 & 5390 & -70761 & -614 & 699 \\
\hline 5489 & -68629 & -500 & -6.2 & $3.7 \mathrm{E}-04$ & 2588 & 4.7 & 5489 & -70960 & -941 & 547 \\
\hline 5489 & -68629 & -750 & -6.0 & $4.4 \mathrm{E}-04$ & 2378 & 3.9 & 5283 & -70658 & -984 & 616 \\
\hline 5489 & -68629 & -1000 & -6.1 & $5.0 \mathrm{E}-04$ & 2655 & 7.1 & 5486 & -70928 & -1349 & 373 \\
\hline 6489 & -68629 & -250 & -4.9 & $1.1 \mathrm{E}-02$ & 563 & 0.5 & 6367 & -68798 & 186 & 1071 \\
\hline 6489 & -68629 & -500 & -5.3 & $5.7 \mathrm{E}-03$ & 902 & 2.2 & 6355 & -68860 & 184 & 413 \\
\hline 6489 & -68629 & -750 & -6.0 & $4.2 \mathrm{E}-04$ & 2915 & 6.2 & 6204 & -71250 & -1063 & 467 \\
\hline 6489 & -68629 & -1000 & -6.0 & 4.7E-04 & 2988 & 5.0 & 6199 & -71248 & -1229 & 600 \\
\hline Avg & & & -5.8 & 1.1E-03 & 2898 & 7.9 & & & & 365 \\
\hline
\end{tabular}

Table 4.4. Summary stream trace information. Quantities are averages over the 24 stream traces for each realization.

\begin{tabular}{|l|l|l|l|l|l|}
\hline & $\begin{array}{l}\mathbf{l o g}_{\mathbf{1 0}} \mathbf{K} \\
(\mathbf{K} \text { in } \mathbf{~ m} / \mathbf{s})\end{array}$ & $\phi$ & $\mathbf{L}(\mathbf{m})$ & $\mathbf{t}(\mathbf{y r})$ & $\mathbf{v}(\mathbf{m} / \mathbf{y r})$ \\
\hline Open Model & & & & & \\
\hline C001 & -5.6 & $1.9 \mathrm{E}-03$ & 1887 & 3.7 & 513 \\
\hline C002 & -5.7 & $2.4 \mathrm{E}-03$ & 1856 & 3.1 & 599 \\
\hline C003 & -5.6 & $4.6 \mathrm{E}-03$ & 1841 & 3.0 & 608 \\
\hline C004 & -5.7 & $3.4 \mathrm{E}-03$ & 1784 & 3.6 & 497 \\
\hline C005 & -5.7 & $4.3 \mathrm{E}-03$ & 1814 & 3.2 & 568 \\
\hline Avg & $\mathbf{- 5 . 7}$ & $\mathbf{3 . 3 E}-\mathbf{0 3}$ & $\mathbf{1 8 3 6}$ & $\mathbf{3 . 3}$ & $\mathbf{5 5 7}$ \\
\hline Closed Model & & & & & \\
\hline J001 & -5.8 & $1.1 \mathrm{E}-03$ & 2898 & 7.9 & 365 \\
\hline J002 & -5.9 & $1.2 \mathrm{E}-03$ & 3030 & 7.7 & 395 \\
\hline J003 & -5.8 & $5.0 \mathrm{E}-04$ & 3043 & 7.6 & 401 \\
\hline J004 & -5.9 & $1.4 \mathrm{E}-03$ & 3124 & 9.2 & 340 \\
\hline J005 & -5.9 & $1.1 \mathrm{E}-03$ & 2956 & 7.4 & 402 \\
\hline Avg & $\mathbf{- 5 . 9}$ & $\mathbf{1 . 1 E}-\mathbf{0 3}$ & $\mathbf{3 0 1 0}$ & $\mathbf{8 . 0}$ & $\mathbf{3 8 1}$ \\
\hline
\end{tabular}




\section{Transient Response to LTPT}

\subsection{Test description and performance measures}

The long-term pump test (LTPT) is designed to investigate flow behavior in the vicinity of the Tsukiyoshi fault. Test specifications call for two intervals in well MIU-2 to be pumped one at a time at a rate of $20 \mathrm{~L} / \mathrm{min}$ for a two-week period, followed by a two-week rest period during which no pumping occurs. The first pumping interval is open above the Tsukiyoshi fault between $\mathrm{z}=-542$ masl and $\mathrm{z}=-642$ masl. The second pumping interval is open below the Tsukiyoshi fault between $\mathrm{z}=-748$ masl and $\mathrm{z}=-776$ masl.

Well MIU-2 is located near the center of the 4 by $6 \mathrm{~km}$ model $(\mathrm{x}=5433 \mathrm{~m}, \mathrm{y}=-68552 \mathrm{~m}$; Figure 2.1) and pressures will be monitored in the pumping intervals there and at the following locations:

Wells MIU-1, MIU-3: elevations: 100, $-250,-500,-750,-1000$ masl

Wells DH-2, DH-4, DH-9: elevations: $100,-250,-500,-750,-1000$ masl

Well TH-8: elevations: 200, 100 masl

The key performance measures at each monitoring location are the amount and the time of the maximum head drop and the arrival time of the peak of the first time-derivative of head. Additionally, plots of pressure transients at all monitoring locations provide an overview of the responses during the tests for different model realizations and boundary conditions.

\subsection{Modeling approach}

The same model used for the steady flow and transport calculations is used to model the LTPT. The lateral grid discretization $(100 \mathrm{~m})$ is rather coarse compared to some of the inter-well distances. For example, the grid columns containing Wells MIU-1, MIU-2, and MIU-3 are all adjacent to one another. Hence, we cannot expect all the details of observed pressure transients to be reproduced by the model. Vertically, the pumping interval locations must be adjusted to fit the grid discretization. Each interval is located in the high-K plane adjacent to the low-K plane representing the Tsukiyoshi fault. The model elevations are $\mathrm{z}=-450$ to -550 masl for the upper pumping interval and $\mathrm{z}=-850$ to -950 masl for the lower pumping interval.

An analytical solution (Thiem, 1906; Peaceman, 1978) may be applied to convert the pressure calculated in the pumping grid block $\left(P_{i j \mathrm{k}}\right.$, an average pressure over the 100 by $100 \mathrm{~m}$ extent of the grid block) to the pressure expected at the well itself, $P_{w}$ :

$$
P_{w}=P_{i j k}+\frac{Q \ln \left(r_{e f f} / r_{w}\right)}{2 \pi K \Delta z},
$$

where $Q$ is volumetric pumping rate, $K$ and $\Delta z$ are the hydraulic conductivity and thickness, respectively, of the grid block from which pumping occurs, $r_{w}$ is wellbore radius, and effective 
radius $r_{\text {eff }}$ is defined as $r_{\text {eff }}=0.14\left(\Delta x^{2}+\Delta y^{2}\right)^{1 / 2}$, with $\Delta x$ and $\Delta y$ the lateral dimensions of the grid block. Note that Equation (5.1) uses constant hydrologic properties equal to the properties of the pumping interval grid block, which makes the pumping interval pressure response very sensitive to the grid block permeability. (An alternative approach would be for the conversion to use mean properties of the rock type in which the pumping interval is found). Also note that Equation (5.1) was derived for two-dimensional (radial) flow through a homogeneous medium; it is not strictly applicable to the present flow conditions.

Two minor changes are made to the new base case models for the LTPT. First, the Tono mine is included as a constant flow boundary condition. If flow rate observations at the mine indicate a decrease in flow during the LTPT, the model will be able to incorporate these changes by assigning a time-varying mine outflow rate or by converting the constant-flow boundary to a constant-head boundary condition. Second, all boundary head values are increased by $100 \mathrm{~m}$. Because flow is sensitive to head differences only, the latter change does not affect the flow field. Its only purpose is to keep all pressures during the pump test above atmospheric pressure so that the water remains in the liquid phase.

For modeling the transient flow of the LTPT, it is necessary to assign a specific storage value $S_{s}$ for each grid block. (The steady-state flow conditions examined previously are not sensitive to $\left.S_{S}\right)$. Specific storage is defined as

$$
S_{s}=\phi C_{w}+\alpha,
$$

where $\phi$ is porosity, $C_{w}$ is the compressibility of water $\left(\sim 4.5^{1} 10^{-6} 1 / \mathrm{m}\right)$, and $\alpha$ is the compressibility of rock. Following Terzaghi's definition of effective stress, we assume that under well-testing conditions, $\alpha$ may be approximated by

$$
\alpha=\frac{1}{V} \frac{\partial V}{\partial P} \approx \frac{1}{1-\phi} \frac{\partial \phi}{\partial P}
$$

where $V$ is rock volume.

Analysis of a previous well test conducted at the MIU site found $S_{s}=10^{-7} 1 / \mathrm{m}$ (Takeuchi et al., 2001 ) for the granitic rocks. For a typical granite porosity value of $410^{-4}$, assuming $S_{S}=10^{-7} 1 / \mathrm{m}$ in Equation (5.2) yields $\alpha=9.8 \cdot 10^{-8} 1 / \mathrm{m}$. This value of $\alpha$ is much bigger than $\phi C_{w}$, implying that well-test analysis would be unlikely to provide much information on $\phi$ itself.

Figure 5.1 shows $S_{s}$ values inferred from slug tests for several wells in the Tono area. $S_{s}$ shows a generally decreasing trend with increasing depth, which is reasonable considering the increase in lithostatic pressure with depth, but the spread in values is enormous - 15 orders of magnitude. Limitations on the ability of slug tests to provide reliable values of $S_{S}$ have been documented previously (Karasaki, 1987), and the large range of values shown in Figure 5.1 supports this. However, it may still be useful to compare general features of the slug-test $S_{S}$ values with theoretical values based on Equation (5.2), to investigate the interplay of water $\left(C_{w}\right)$ and rock $(\alpha)$ compressibility. 
In general, if using model properties in Equation (5.2) under-predicts field values of $S_{s}$, one could increase either $\phi$ or $\alpha$ in the model. For the granitic rocks, we found that to achieve $S_{s}=$ $10^{-7} 1 / \mathrm{m}$, we could use $\alpha=9.8 \cdot 10^{-8} 1 / \mathrm{m}$ along with our usual value of $\phi$. Formally, we could have just as easily increased $\phi$ from $4 \cdot 10^{-4}$ to 0.022 , while assuming $\alpha$ is negligible. However, this approach would not be physically motivated. For the sedimentary rocks (elevations above 100 masl), if the rock compressibility is neglected $\left(S_{s}=\phi C_{w}\right)$, then using $\phi=0.2$ yields $S_{s}=$ $9 \cdot 10^{-7} 1 / \mathrm{m}$, a value that greatly under-predicts much of the slug-test data (Figure 5.1). Because $\phi$ cannot be greater than one, in order to increase $S_{S}$ significantly, $\alpha$ must be non-zero. We assume that a 'normalized' rock compressibility $\alpha^{\prime}=\alpha / \phi$ does not vary much between rock types. For the granitic rocks, $\alpha^{\prime}=9.8 \cdot 10^{-8} / 4 \cdot 10^{-4}=2.5 \cdot 10^{-4} 1 / \mathrm{m}$. Applying this same $\alpha^{\prime}$ to the sedimentary rocks yields $\alpha=\alpha^{\prime} \phi=5 \cdot 10^{-5} 1 / \mathrm{m}$, which Figure 5.1 shows yields an $S_{s}$ value in the middle of the slug-test range.

For simulations of the LTPT, we write Equation (5.2) as

$$
S_{s}=\phi C_{w}+\alpha=\phi\left(C_{w}+\alpha^{\prime}\right)
$$

with $C_{w}=4.5 \cdot 10^{-5} 1 / \mathrm{m}$ and $\alpha^{\prime}=2.5 \cdot 10^{-4} 1 / \mathrm{m}$ constant over the entire model. Then, the actual porosity of each grid block is multiplied by $\left(C_{w}+\alpha^{\prime}\right)$ to produce $S_{s}$ for that grid block.

\subsection{Results}

Five realizations each of the open and closed versions of the new base case are used to simulate the LTPT. Figure 5.2 shows the pressure transients at all the pressure-monitoring locations for one realization of the open model. Drawdowns increase monotonically during the pumping periods for all locations. The end of the pumping period is the time at which the maximum pressure change occurs for most locations. We simulated the whole sequence including two sets of pumping and recovery in one simulation. After the two weeks of recovery following the first pumping period, the system had not fully recovered back to the original ambient condition. This was particularly evident in distant wells.

The spatial distributions of maximum drawdown for the two tests are shown in Figure 5.3. The Tsukiyoshi fault does not act like a completely closed boundary, but it does damp the propagation of pressure changes, as demonstrated by comparing the responses to pumping above and below the fault.

Figure 5.4 shows the pressure transients for another realization of the open model, to illustrate the variability between realizations. Although the general pressure trends are the same for both realizations, large differences do exist, especially for monitoring locations near the pumping well. The large differences between realizations are not surprising given the coarseness of the grid compared to the distance between pumping and observation intervals.

Figure 5.5 shows the pressure transients for a realization of the closed model. Comparing Figures 5.2 and 5.5 illustrates the effect of lateral boundary conditions. The near-field pressure responses are indistinguishable for the open and closed models. Slightly larger pressure 
differences are seen in the most distant observation wells for the closed model. However, the responses themselves are so small that it does not appear likely that it will be possible to use well-test analysis to determine whether the open or closed models provide a more realistic representation of field conditions.

Performance measures for the various monitoring locations are summarized in Tables 5.1 and 5.2 for the open and closed models, respectively. The pressure changes shown are grid-block averages. Table 5.3 shows the pressure changes for the pumped intervals themselves, calculated with Equation (5.1), for the closed model (results for the open model are nearly the same).

Table 5.1. Performance measures for the new base case-open model. Averages are taken over five realizations.

\begin{tabular}{|c|c|c|c|c|c|c|c|c|c|c|}
\hline \multirow{2}{*}{$\begin{array}{l}\text { TEST } 1 \\
\text { Interval }\end{array}$} & \multirow{2}{*}{$\begin{array}{l}\text { Elev. } \\
\text { (masl) }\end{array}$} & \multicolumn{3}{|c|}{ Time of Max $\Delta \mathrm{P}$ (day) } & \multicolumn{3}{|c|}{$\operatorname{Max} \Delta \mathrm{P}(\mathrm{kPa})$} & \multicolumn{3}{|c|}{ Time of Max dP/dt (day) } \\
\hline & & Avg & Min & Max & Avg & Min & $\operatorname{Max}$ & Avg & Min & Max \\
\hline MIU-2 upper & -500 & 14.0 & 14.0 & 14.0 & 36.41 & 18.23 & 84.36 & $8.9 \mathrm{E}-07$ & $8.9 \mathrm{E}-07$ & $8.9 \mathrm{E}-07$ \\
\hline MIU-2 lower & -900 & 14.0 & 14.0 & 14.0 & 1.04 & 0.77 & 1.31 & 0.24 & 0.05 & 0.31 \\
\hline MIU-1 & 100 & 14.0 & 14.0 & 14.0 & 0.68 & 0.15 & 1.21 & 0.22 & 0.13 & 0.31 \\
\hline MIU-1 & -250 & 14.0 & 14.0 & 14.0 & 3.84 & 2.65 & 5.24 & 0.04 & 0.02 & 0.05 \\
\hline MIU-1 & -500 & 14.0 & 14.0 & 14.0 & 11.45 & 7.43 & 13.64 & $2.3 \mathrm{E}-03$ & 1.7E-03 & $4.0 \mathrm{E}-03$ \\
\hline MIU-1 & -750 & 14.0 & 14.0 & 14.0 & 3.58 & 1.83 & 4.53 & 0.08 & 0.02 & 0.13 \\
\hline MIU-1 & -1000 & 14.0 & 14.0 & 14.0 & 1.29 & 1.08 & 1.48 & 0.37 & 0.13 & 0.73 \\
\hline MIU-3 & 100 & 14.0 & 14.0 & 14.0 & 0.57 & 0.13 & 1.01 & 0.17 & 0.13 & 0.31 \\
\hline MIU-3 & -250 & 14.0 & 14.0 & 14.0 & 1.97 & 1.39 & 2.71 & 0.13 & 0.13 & 0.13 \\
\hline MIU-3 & -500 & 14.0 & 14.0 & 14.0 & 3.18 & 1.07 & 5.17 & 0.08 & 4.0E-03 & 0.13 \\
\hline MIU-3 & -750 & 14.0 & 14.0 & 14.0 & 1.14 & 0.73 & 1.61 & 0.17 & 0.02 & 0.31 \\
\hline MIU-3 & -1000 & 14.0 & 14.0 & 14.0 & 0.80 & 0.65 & 1.06 & 0.32 & 0.13 & 0.73 \\
\hline $\mathrm{DH}-2$ & 100 & 26.4 & 21.5 & 28.0 & 0.01 & 0.01 & 0.02 & 14.00 & 14.00 & 14.00 \\
\hline $\mathrm{DH}-2$ & -250 & 14.3 & 14.3 & 14.3 & 0.20 & 0.14 & 0.27 & 1.75 & 1.75 & 1.75 \\
\hline $\mathrm{DH}-2$ & -500 & 14.4 & 14.3 & 14.6 & 0.25 & 0.16 & 0.35 & 1.75 & 1.75 & 1.75 \\
\hline $\mathrm{DH}-2$ & -750 & 14.4 & 14.3 & 14.6 & 0.26 & 0.18 & 0.32 & 4.81 & 1.75 & 14.00 \\
\hline $\mathrm{DH}-2$ & -1000 & 14.4 & 14.3 & 14.6 & 0.29 & 0.20 & 0.34 & 1.75 & 1.75 & 1.75 \\
\hline $\mathrm{DH}-4$ & 100 & 14.2 & 14.2 & 14.2 & 0.03 & 0.02 & 0.05 & 1.24 & 0.73 & 1.75 \\
\hline $\mathrm{DH}-4$ & -250 & 14.2 & 14.2 & 14.2 & 0.11 & 0.08 & 0.13 & 1.24 & 0.73 & 1.75 \\
\hline $\mathrm{DH}-4$ & -500 & 14.2 & 14.2 & 14.2 & 0.13 & 0.09 & 0.16 & 1.75 & 1.75 & 1.75 \\
\hline $\mathrm{DH}-4$ & -750 & 14.2 & 14.2 & 14.3 & 0.16 & 0.13 & 0.20 & 1.75 & 1.75 & 1.75 \\
\hline $\mathrm{DH}-4$ & -1000 & 14.3 & 14.3 & 14.3 & 0.16 & 0.13 & 0.19 & 4.81 & 1.75 & 14.00 \\
\hline $\mathrm{DH}-9$ & 100 & 14.5 & 14.3 & 14.6 & 0.08 & 0.03 & 0.18 & 1.75 & 1.75 & 1.75 \\
\hline $\mathrm{DH}-9$ & -250 & 14.5 & 14.3 & 14.6 & 0.14 & 0.06 & 0.20 & 1.75 & 1.75 & 1.75 \\
\hline $\mathrm{DH}-9$ & -500 & 14.6 & 14.6 & 14.6 & 0.15 & 0.10 & 0.20 & 7.87 & 1.75 & 14.00 \\
\hline $\mathrm{DH}-9$ & -750 & 14.7 & 14.6 & 15.1 & 0.17 & 0.13 & 0.20 & 10.94 & 1.75 & 14.00 \\
\hline $\mathrm{DH}-9$ & -1000 & 14.7 & 14.6 & 15.1 & 0.18 & 0.13 & 0.24 & 5.42 & 1.75 & 14.00 \\
\hline $\mathrm{TH}-8$ & 200 & 14.1 & 14.0 & 14.1 & 0.02 & 3.1E-03 & 0.06 & 0.73 & 0.73 & 0.73 \\
\hline TH-8 & 100 & 14.1 & 14.1 & 14.1 & 0.15 & 0.11 & 0.17 & 0.73 & 0.73 & 0.73 \\
\hline
\end{tabular}


Table 5.1. Open model continued.

\begin{tabular}{|c|c|c|c|c|c|c|c|c|c|c|}
\hline TEST 2 & Elev. & Time & $f \operatorname{Max}$ & $\mathrm{P}$ (day) & $\operatorname{Max} \Delta \mathrm{F}$ & $(\mathrm{kPa})$ & & Time of I & lax dP/dt & (day) \\
\hline Interval & (masl) & Avg & Min & Max & Avg & Min & Max & Avg & Min & Max \\
\hline MIU-2 upper & -500 & 14.0 & 14.0 & 14.0 & 0.96 & 0.60 & 1.32 & 0.29 & 0.04 & 0.47 \\
\hline MIU-2 lower & -900 & 14.0 & 14.0 & 14.0 & 140.90 & 19.78 & 441.54 & 6.4E-05 & 6.4E-05 & 6.4E-05 \\
\hline MIU-1 & 100 & 14.1 & 14.0 & 14.1 & 0.13 & 0.04 & 0.24 & 3.42 & 0.47 & 14.00 \\
\hline MIU-1 & -250 & 14.0 & 14.0 & 14.0 & 0.57 & 0.44 & 0.67 & 0.55 & 0.47 & 0.87 \\
\hline MIU-1 & -500 & 14.0 & 14.0 & 14.0 & 0.94 & 0.60 & 1.31 & 0.28 & 0.07 & 0.47 \\
\hline MIU-1 & -750 & 14.0 & 14.0 & 14.0 & 5.47 & 2.59 & 12.84 & 0.03 & 0.01 & 0.04 \\
\hline MIU-1 & -1000 & 14.0 & 14.0 & 14.0 & 10.36 & 6.45 & 13.43 & 0.05 & 0.02 & 0.13 \\
\hline MIU-3 & 100 & 14.1 & 14.0 & 14.1 & 0.12 & 0.04 & 0.20 & 0.79 & 0.47 & 0.87 \\
\hline MIU-3 & -250 & 14.0 & 14.0 & 14.0 & 1.06 & 0.78 & 1.32 & 0.47 & 0.47 & 0.47 \\
\hline MIU-3 & -500 & 14.0 & 14.0 & 14.0 & 2.34 & 1.88 & 2.80 & 0.21 & 0.07 & 0.47 \\
\hline MIU-3 & -750 & 14.0 & 14.0 & 14.0 & 4.53 & 3.28 & 6.76 & 0.03 & 0.01 & 0.07 \\
\hline MIU-3 & -1000 & 14.0 & 14.0 & 14.0 & 8.51 & 6.34 & 13.49 & 0.02 & 0.01 & 0.02 \\
\hline $\mathrm{DH}-2$ & 100 & 22.6 & 14.0 & 28.0 & 0.02 & 0.01 & 0.03 & 11.20 & 8.1E-04 & 14.01 \\
\hline $\mathrm{DH}-2$ & -250 & 14.6 & 14.6 & 14.6 & 0.11 & 0.07 & 0.14 & 5.25 & 3.06 & 14.00 \\
\hline $\mathrm{DH}-2$ & -500 & 14.6 & 14.6 & 14.6 & 0.16 & 0.12 & 0.20 & 3.06 & 3.06 & 3.06 \\
\hline $\mathrm{DH}-2$ & -750 & 14.6 & 14.6 & 14.6 & 0.18 & 0.15 & 0.21 & 7.44 & 3.06 & 14.00 \\
\hline $\mathrm{DH}-2$ & -1000 & 14.6 & 14.6 & 14.6 & 0.22 & 0.17 & 0.27 & 9.62 & 3.06 & 14.00 \\
\hline $\mathrm{DH}-4$ & 100 & 14.4 & 14.3 & 14.6 & 0.02 & 0.01 & 0.04 & 4.11 & 1.63 & 14.00 \\
\hline $\mathrm{DH}-4$ & -250 & 14.3 & 14.3 & 14.3 & 0.06 & 0.05 & 0.08 & 4.11 & 1.63 & 14.00 \\
\hline $\mathrm{DH}-4$ & -500 & 14.3 & 14.3 & 14.3 & 0.08 & 0.07 & 0.10 & 1.63 & 1.63 & 1.63 \\
\hline $\mathrm{DH}-4$ & -750 & 14.3 & 14.3 & 14.3 & 0.11 & 0.09 & 0.16 & 4.11 & 1.63 & 14.00 \\
\hline $\mathrm{DH}-4$ & -1000 & 14.3 & 14.2 & 14.3 & 0.13 & 0.10 & 0.21 & 4.11 & 1.63 & 14.00 \\
\hline $\mathrm{DH}-9$ & 100 & 14.6 & 14.6 & 14.6 & 0.13 & 0.06 & 0.27 & 3.06 & 3.06 & 3.06 \\
\hline DH-9 & -250 & 14.6 & 14.6 & 14.6 & 0.36 & 0.21 & 0.48 & 3.06 & 3.06 & 3.06 \\
\hline $\mathrm{DH}-9$ & -500 & 14.6 & 14.3 & 14.6 & 0.47 & 0.40 & 0.62 & 2.78 & 1.63 & 3.06 \\
\hline $\mathrm{DH}-9$ & -750 & 14.4 & 14.3 & 14.6 & 0.60 & 0.50 & 0.69 & 1.92 & 1.63 & 3.06 \\
\hline $\mathrm{DH}-9$ & -1000 & 14.4 & 14.3 & 14.6 & 0.67 & 0.54 & 0.79 & 1.63 & 1.63 & 1.63 \\
\hline TH-8 & 200 & 14.1 & 14.1 & 14.2 & 0.04 & $4.3 \mathrm{E}-03$ & 0.10 & 6.12 & 0.87 & 14.00 \\
\hline TH-8 & 100 & 14.1 & 14.1 & 14.2 & 0.22 & 0.20 & 0.27 & 0.87 & 0.87 & 0.87 \\
\hline
\end{tabular}


Table 5.2. Performance measures for the new base case-closed model. Averages are taken over five realizations.

\begin{tabular}{|c|c|c|c|c|c|c|c|c|c|c|}
\hline \multirow{2}{*}{\begin{tabular}{|l|} 
TEST 1 \\
Interval \\
\end{tabular}} & \multirow{2}{*}{$\begin{array}{l}\text { Elev. } \\
\text { (masl) }\end{array}$} & \multicolumn{3}{|c|}{ Time of Max $\Delta \mathrm{P}$ (day) } & \multicolumn{3}{|c|}{$\operatorname{Max} \Delta \mathrm{P}(\mathrm{kPa})$} & \multicolumn{3}{|c|}{ Time of Max dP/dt (day) } \\
\hline & & Avg & Min & Max & Avg & Min & Max & Avg & Min & Max \\
\hline MIU-2 upper & -500 & 14.0 & 14.0 & 14.0 & 31.81 & 13.07 & 84.46 & 8.9E-07 & 8.9E-07 & 8.9E-07 \\
\hline MIU-2 lower & -900 & 14.0 & 14.0 & 14.0 & 1.05 & 0.68 & 1.42 & 0.26 & 0.05 & 0.31 \\
\hline MIU-1 & 100 & 14.0 & 14.0 & 14.0 & 0.74 & 0.16 & 1.22 & 0.16 & 0.13 & 0.31 \\
\hline MIU-1 & -250 & 14.0 & 14.0 & 14.0 & 4.09 & 2.70 & 5.31 & 0.04 & 0.02 & 0.05 \\
\hline MIU-1 & -500 & 14.0 & 14.0 & 14.0 & 11.01 & 7.49 & 13.73 & 2.1E-03 & 1.7E-03 & 4.0E-03 \\
\hline MIU-1 & -750 & 14.0 & 14.0 & 14.0 & 3.51 & 1.91 & 4.65 & 0.09 & 0.02 & 0.13 \\
\hline MIU-1 & -1000 & 14.0 & 14.0 & 14.0 & 1.36 & 1.17 & 1.60 & 0.36 & 0.13 & 0.73 \\
\hline MIU-3 & 100 & 14.0 & 14.0 & 14.0 & 0.64 & 0.14 & 1.02 & 0.16 & 0.13 & 0.31 \\
\hline MIU-3 & -250 & 14.0 & 14.0 & 14.0 & 2.02 & 1.46 & 2.76 & 0.11 & 0.05 & 0.13 \\
\hline MIU-3 & -500 & 14.0 & 14.0 & 14.0 & 3.28 & 1.15 & 5.26 & 0.07 & 4.0E-03 & 0.13 \\
\hline MIU-3 & -750 & 14.0 & 14.0 & 14.0 & 1.13 & 0.71 & 1.72 & 0.15 & 0.02 & 0.31 \\
\hline MIU-3 & -1000 & 14.0 & 14.0 & 14.0 & 0.85 & 0.62 & 1.18 & 0.41 & 0.13 & 0.73 \\
\hline $\mathrm{DH}-2$ & 100 & 26.7 & 21.5 & 28.0 & 0.02 & 0.01 & 0.04 & 14.00 & 14.00 & 14.00 \\
\hline $\mathrm{DH}-2$ & -250 & 14.4 & 14.3 & 14.6 & 0.25 & 0.20 & 0.35 & 4.20 & 1.75 & 14.00 \\
\hline $\mathrm{DH}-2$ & -500 & 14.4 & 14.3 & 14.6 & 0.33 & 0.26 & 0.46 & 4.20 & 1.75 & 14.00 \\
\hline $\mathrm{DH}-2$ & -750 & 14.6 & 14.3 & 14.6 & 0.36 & 0.29 & 0.46 & 4.20 & 1.75 & 14.00 \\
\hline $\mathrm{DH}-2$ & -1000 & 14.6 & 14.6 & 14.6 & 0.40 & 0.32 & 0.48 & 6.65 & 1.75 & 14.00 \\
\hline $\mathrm{DH}-4$ & 100 & 14.4 & 14.3 & 14.6 & 0.08 & 0.05 & 0.10 & 4.20 & 1.75 & 14.00 \\
\hline $\mathrm{DH}-4$ & -250 & 14.3 & 14.3 & 14.3 & 0.32 & 0.21 & 0.37 & 4.20 & 1.75 & 14.00 \\
\hline DH-4 & -500 & 14.3 & 14.3 & 14.3 & 0.39 & 0.28 & 0.46 & 1.75 & 1.75 & 1.75 \\
\hline $\mathrm{DH}-4$ & -750 & 14.4 & 14.3 & 14.6 & 0.43 & 0.32 & 0.53 & 4.20 & 1.75 & 14.00 \\
\hline $\mathrm{DH}-4$ & -1000 & 14.6 & 14.6 & 14.6 & 0.46 & 0.36 & 0.57 & 6.65 & 1.75 & 14.00 \\
\hline $\mathrm{DH}-9$ & 100 & 14.5 & 14.3 & 14.6 & 0.08 & 0.03 & 0.20 & 6.65 & 1.75 & 14.00 \\
\hline $\mathrm{DH}-9$ & -250 & 14.7 & 14.6 & 15.1 & 0.17 & 0.10 & 0.24 & 4.20 & 1.75 & 14.00 \\
\hline $\mathrm{DH}-9$ & -500 & 14.9 & 14.6 & 15.1 & 0.19 & 0.15 & 0.24 & 7.62 & 1.75 & 14.00 \\
\hline $\mathrm{DH}-9$ & -750 & 14.9 & 14.6 & 15.1 & 0.22 & 0.18 & 0.26 & 12.03 & 4.17 & 14.00 \\
\hline $\mathrm{DH}-9$ & -1000 & 14.9 & 14.6 & 15.1 & 0.23 & 0.18 & 0.30 & 12.03 & 4.17 & 14.00 \\
\hline TH-8 & 200 & 14.1 & 14.0 & 14.2 & 0.03 & $3.5 \mathrm{E}-03$ & 0.08 & 3.39 & 0.73 & 14.00 \\
\hline TH-8 & 100 & 14.1 & 14.0 & 14.1 & 0.17 & 0.09 & 0.21 & 0.65 & 0.31 & 0.73 \\
\hline
\end{tabular}


Table 5.2. Closed model continued.

\begin{tabular}{|c|c|c|c|c|c|c|c|c|c|c|}
\hline \multirow{2}{*}{\begin{tabular}{|l|} 
TEST 2 \\
Interval \\
\end{tabular}} & \multirow{2}{*}{$\begin{array}{l}\text { Elev. } \\
\text { (masl) }\end{array}$} & \multicolumn{3}{|c|}{ Time of Max $\Delta \mathrm{P}$ (day) } & \multicolumn{3}{|c|}{$\operatorname{Max} \Delta \mathrm{P}(\mathrm{kPa})$} & \multicolumn{3}{|c|}{ Time of Max dP/dt (day) } \\
\hline & & Avg & Min & Max & Avg & Min & Max & Avg & Min & Max \\
\hline MIU-2 upper & -500 & 14.0 & 14.0 & 14.0 & 1.08 & 0.70 & 1.46 & 0.29 & 0.04 & 0.47 \\
\hline MIU-2 lower & -900 & 14.0 & 14.0 & 14.0 & 141.17 & 20.08 & 441.83 & 6.4E-05 & 6.4E-05 & 6.4E-05 \\
\hline MIU-1 & 100 & 14.1 & 14.1 & 14.2 & 0.16 & 0.05 & 0.27 & 0.79 & 0.47 & 0.87 \\
\hline MIU-1 & -250 & 14.0 & 14.0 & 14.0 & 0.67 & 0.52 & 0.76 & 0.55 & 0.47 & 0.87 \\
\hline MIU-1 & -500 & 14.0 & 14.0 & 14.0 & 1.07 & 0.70 & 1.44 & 0.28 & 0.07 & 0.47 \\
\hline MIU-1 & -750 & 14.0 & 14.0 & 14.0 & 5.64 & 2.75 & 13.00 & 0.03 & 0.01 & 0.04 \\
\hline MIU-1 & -1000 & 14.0 & 14.0 & 14.0 & 10.59 & 6.70 & 13.64 & 0.05 & 0.02 & 0.13 \\
\hline MIU-3 & 100 & 14.1 & 14.0 & 14.1 & 0.14 & 0.05 & 0.23 & 0.79 & 0.47 & 0.87 \\
\hline MIU-3 & -250 & 14.0 & 14.0 & 14.0 & 1.19 & 0.89 & 1.46 & 0.47 & 0.47 & 0.47 \\
\hline MIU-3 & -500 & 14.0 & 14.0 & 14.0 & 2.53 & 2.03 & 3.00 & 0.21 & 0.07 & 0.47 \\
\hline MIU-3 & -750 & 14.0 & 14.0 & 14.0 & 4.77 & 3.49 & 7.05 & 0.03 & 0.01 & 0.07 \\
\hline MIU-3 & -1000 & 14.0 & 14.0 & 14.0 & 8.77 & 6.58 & 13.76 & 0.02 & 0.01 & 0.02 \\
\hline $\mathrm{DH}-2$ & 100 & 26.7 & 21.5 & 28.0 & 0.03 & 0.02 & 0.05 & 8.40 & 1.2E-05 & 14.00 \\
\hline $\mathrm{DH}-2$ & -250 & 15.1 & 15.1 & 15.1 & 0.19 & 0.14 & 0.24 & 5.78 & 3.06 & 14.00 \\
\hline $\mathrm{DH}-2$ & -500 & 15.0 & 14.6 & 15.1 & 0.27 & 0.22 & 0.33 & 7.97 & 3.06 & 14.00 \\
\hline $\mathrm{DH}-2$ & -750 & 15.0 & 14.6 & 15.1 & 0.32 & 0.25 & 0.36 & 9.62 & 3.06 & 14.00 \\
\hline $\mathrm{DH}-2$ & -1000 & 15.0 & 14.6 & 15.1 & 0.38 & 0.30 & 0.44 & 14.00 & 14.00 & 14.00 \\
\hline $\mathrm{DH}-4$ & 100 & 14.8 & 14.6 & 15.1 & 0.07 & 0.05 & 0.11 & 7.15 & 1.63 & 14.00 \\
\hline $\mathrm{DH}-4$ & -250 & 14.6 & 14.6 & 14.6 & 0.27 & 0.24 & 0.32 & 2.78 & 1.63 & 3.06 \\
\hline $\mathrm{DH}-4$ & -500 & 14.6 & 14.6 & 14.6 & 0.35 & 0.31 & 0.38 & 9.62 & 3.06 & 14.00 \\
\hline $\mathrm{DH}-4$ & -750 & 14.7 & 14.6 & 15.1 & 0.43 & 0.37 & 0.48 & 9.62 & 3.06 & 14.00 \\
\hline $\mathrm{DH}-4$ & -1000 & 14.8 & 14.3 & 15.1 & 0.49 & 0.41 & 0.57 & 9.34 & 1.63 & 14.00 \\
\hline $\mathrm{DH}-9$ & 100 & 14.7 & 14.6 & 15.1 & 0.18 & 0.08 & 0.34 & 3.06 & 3.06 & 3.06 \\
\hline $\mathrm{DH}-9$ & -250 & 14.8 & 14.6 & 15.1 & 0.48 & 0.36 & 0.59 & 5.25 & 3.06 & 14.00 \\
\hline $\mathrm{DH}-9$ & -500 & 14.8 & 14.6 & 15.1 & 0.62 & 0.52 & 0.76 & 2.78 & 1.63 & 3.06 \\
\hline DH-9 & -750 & 14.6 & 14.6 & 14.6 & 0.77 & 0.67 & 0.85 & 4.39 & 1.63 & 14.00 \\
\hline $\mathrm{DH}-9$ & -1000 & 14.5 & 14.3 & 14.6 & 0.86 & 0.71 & 1.00 & 4.39 & 1.63 & 14.00 \\
\hline TH-8 & 200 & 14.2 & 14.1 & 14.3 & 0.05 & 0.01 & 0.14 & 6.12 & 0.87 & 14.00 \\
\hline TH-8 & 100 & 14.2 & 14.1 & 14.2 & 0.30 & 0.25 & 0.39 & 0.87 & 0.87 & 0.87 \\
\hline
\end{tabular}


Table 5.3. Pressure responses at pumped interval for the closed model.

\begin{tabular}{|llll|}
\hline \multicolumn{4}{|l|}{ TEST 1 - upper pumped interval } \\
\hline Realization Log $_{10} \mathrm{~K}$ & $\Delta \mathrm{P}_{\mathrm{ijk}}(\mathrm{kPa})$ & $\Delta \mathrm{P}_{\mathrm{w}}(\mathrm{kPa})$ \\
\hline 1 & -6.83 & 84.5 & 300.5 \\
2 & -5.48 & 18.3 & 28.0 \\
3 & -3.63 & 13.1 & 13.2 \\
4 & -5.55 & 20.2 & 31.5 \\
5 & -5.78 & 23.0 & 42.0 \\
\hline Avg & -5.45 & 31.8 & 83.0 \\
Min & -6.83 & 13.1 & 13.2 \\
Max & -3.63 & 84.5 & 300.5 \\
\hline \multicolumn{5}{|c|}{} \\
TEST 2 - lower pumped interval \\
\hline Realization Log $_{10} \mathrm{~K}$ & $\Delta \mathrm{P}_{\mathrm{ijk}}(\mathrm{kPa})$ & $\Delta \mathrm{P}_{\mathrm{w}}(\mathrm{kPa})$ \\
\hline 1 & -7.09 & 71.7 & 463.1 \\
2 & -7.18 & 124.7 & 607.4 \\
3 & -5.57 & 20.1 & 31.9 \\
4 & -8.09 & 441.8 & 4361.3 \\
5 & -4.94 & 47.6 & 50.4 \\
\hline Avg & -6.58 & 141.2 & 1102.8 \\
Min & -8.09 & 20.1 & 31.9 \\
Max & -4.94 & 441.8 & 4361.3 \\
\hline
\end{tabular}

The time dependence of the pressure response to the LTPT is largely dependent on the new parameter introduced: the specific storage or rock compressibility. However, the drawdown at large times is not a function of the storage, but of the permeability and the boundary conditions. Among different realizations, Tables 5.1 and 5.2 indicate that the arrival time of the pressure front (time of $\max d P / d t$ ) shows more variability than the magnitude of the drawdown (max $\Delta P$ ). Because the planned pumping rate of the LTPT $(20 \mathrm{~L} / \mathrm{min}=0.333 \mathrm{~kg} / \mathrm{s})$ is very small compared to all entries in the water budget (Table 4.1), it is not surprising that pump-test responses are not very sensitive to distant model boundary conditions.

For both versions of the new base case, the top surface of the model is a constant head boundary condition. Therefore, as pressures in the model decrease due to pumping, the flow of water into the model representing recharge increases, which may not be realistic (unless we suppose recharge occurs from a ponded water source rather than from precipitation). Figure 5.6 shows the pressure transients for a realization of the closed version of the new base case for which the constant-head surface boundary condition has been replaced by a constant-flux boundary condition. Fluxes are taken from the constant-head model under steady-state conditions. Slightly larger drawdowns are apparent for several distant observation locations, but drawdowns for nearby wells are little affected by the switch from a constant-head to constant-flux surface boundary (compare Figures 5.5 and 5.6).

A better surface representation might be to specify constant fluxes for grid blocks that show inflow to the steady-state model (representing infiltration/recharge), and constant heads for grid blocks that show outflow from the steady-state model (representing spring discharge or subsurface to surface flow). Given the irregular distribution of inflow and outflow over the top boundary (Figure 4.3), such an assignment would be possible but nontrivial to implement. For 
the low pumping rate of the LTPT, the choice of surface boundary conditions is not critical, but for a larger pumping rate, it could have important effects on the modeled drawdowns.

\section{Thermal Analyses}

The purpose of the thermal analyses is twofold. First, we want to assess the error made by doing isothermal simulations of steady-state flow fields and the accompanying tracer transport. Second, we want to determine whether or not borehole temperature profiles provide any information on regional or local hydrology that can help us better constrain our models.

\subsection{General features of measured temperature profiles}

Temperature versus depth profiles have been measured in 24 wells in the Tono area. Of these, 16 extend over $200 \mathrm{~m}$ below the ground surface, making them amenable to an analysis of the basin-scale interplay between conductive and convective heat flow. In six wells, temperature measurements were repeated several months or years later, allowing an assessment of transient effects and instrument reliability.

Figure 6.1 shows all the available temperature profiles that extend more than $200 \mathrm{~m}$ below the surface. The purpose of this display is to provide a general introduction to the kinds of temperature variations observed in the field, which are enumerated below. Details of individual temperature profiles are analyzed later.

\section{Near-surface effects}

Temperatures just below the ground surface vary from about $5^{\circ} \mathrm{C}$ to $25^{\circ} \mathrm{C}$ among the different profiles, with a mean of about $15^{\circ} \mathrm{C}$. These values are interpreted to reflect the seasonal mean and variation of surface temperature. If the surface temperature variation is idealized as sinusoidal, heat flow is assumed to be purely conductive, and subsurface thermal properties are constant in time and uniform in space, then a simple analytical expression for the temperature $T$ at time $t$ and depth $z$ can be applied (Hillel, 1980):

$T(z, t)=T_{0}+T_{1} \exp (-z / D) \cos \left[(2 \pi / \tau)\left(t-t_{0}\right)-z / D\right]$

where $T_{0}, T_{1}, \tau$, and $t_{0}$ are the mean, amplitude, period, and phase lag of the surface temperature variation and $D$ is a penetration depth given by

$D=\sqrt{\frac{\lambda \tau}{\pi C}}$,

with $\lambda$ and $\mathrm{C}$ the thermal conductivity and volumetric heat capacity of the subsurface. Equation (6.1) indicates that surface temperature changes are smoothly (exponentially) damped with depth. For typical subsurface thermal properties, seasonal temperature changes extend no more than about $10 \mathrm{~m}$ below the ground surface. Several of the near-surface temperatures observed in 
the field do follow this pattern, but most do not. Abruptly changing temperatures and deeper penetration of extreme temperatures probably reflect convective heat transport accompanying infiltration or other groundwater movement.

\section{Deep trends}

Below about $300 \mathrm{~m}$ deep, most of the profiles are generally linear with a slope of about $2^{\circ} \mathrm{C}$ per $100 \mathrm{~m}$, which is inferred to represent the regional conductive geothermal gradient. Although the slopes of most profiles are similar, the profiles themselves are offset from one another. Shifting the profiles to account for different surface elevations does not appreciably lessen the offset.

\section{Evidence of localized fluid inflow}

Several profiles show sudden jumps in temperature that suggest localized and/or transient water movement, presumably through high-permeability fractures or faults.

\subsection{3-D uncoupled thermal and flow analysis}

Based on the borehole temperature profiles, the simplest approximation for thermal behavior is a constant temperature gradient of about $2^{\circ} \mathrm{C}$ per $100 \mathrm{~m}$. With TOUGH2, we can assign this linear temperature variation as an initial condition and hold it fixed during the subsequent simulation of steady-state flow. We refer to this procedure as an uncoupled thermal and flow analysis.

As temperature increases with depth, both density $\rho$ and viscosity $\mu$ of water decrease (Figure 6.2). Because the viscosity decrease is much greater, hydraulic conductivity $\mathrm{K}=\rho \mathrm{gk} / \mu$ increases with depth (if intrinsic permeability $\mathrm{k}$ is constant). Isothermal models that are restricted to constant values of $\rho$ and $\mu$ could thus account for increasing temperatures by assigning increasing values of $\mathrm{K}$ with depth. The dependence of $\mu$ on $\mathrm{T}$ is strongly nonlinear, with larger changes for larger $\mathrm{T}$ values.

Steady-state flow and transport simulations were done using a constant surface temperature of $15^{\circ} \mathrm{C}$ and a fixed temperature gradient of $2^{\circ} \mathrm{C}$ per $100 \mathrm{~m}$, for the open and closed versions of the new base case. Water budgets are compared to the corresponding isothermal $\left(20^{\circ} \mathrm{C}\right)$ cases in Table 6.1. The differences are modest, but more flow moves through the model for the nonuniform temperature cases, a reflection of the higher average temperature $\left(45^{\circ} \mathrm{C}\right.$ compared to $\left.20^{\circ} \mathrm{C}\right)$ producing a lower average viscosity $(0.0006 \mathrm{~Pa} \mathrm{sec}$ compared to $0.001 \mathrm{~Pa} \mathrm{sec})$.

Figures 6.3 and 6.4 show cross-sections through the uncoupled models, illustrating the temperature distributions and the stream traces for steady-state flow. Comparison with the isothermal cases (Figures 4.4 and 4.5) shows that the overall pattern of the stream traces is little changed by the addition of a non-uniform temperature. Note that the stream traces for the closed model tend to be deeper than those for the open model, hence they encounter higher temperatures: the average temperature along the stream traces is $27^{\circ} \mathrm{C}$ for the open model and $36^{\circ} \mathrm{C}$ for the closed model. 
Table 6.1. Water budgets for realization 1 of the open and closed versions of the new base case, for various thermal approaches.

\begin{tabular}{|l|l|l|l|l|}
\hline Open Model & Surface & $\begin{array}{l}\text { Toki } \\
\text { River }\end{array}$ & $\begin{array}{l}\text { North } \\
\text { Side }\end{array}$ & $\begin{array}{l}\text { East and } \\
\text { West Sides }\end{array}$ \\
\hline Isothermal & -119 & -7 & 26 & 100 \\
\hline Uncoupled thermal and flow & -124 & -7 & 30 & 101 \\
\hline Coupled thermal and flow & -139 & -11 & 32 & 118 \\
\hline Closed Model & Surface & $\begin{array}{l}\text { Toki } \\
\text { River }\end{array}$ & $\begin{array}{l}\text { Hiyoshi } \\
\text { River }\end{array}$ & \\
\hline Isothermal & 65 & -57 & -8 & \\
\hline Uncoupled thermal and flow & 79 & -71 & -8 & \\
\hline Coupled thermal and flow & 68 & -60 & -7 & \\
\hline
\end{tabular}

Table 6.2 compares the performance measures for the uncoupled thermal and flow models to those of the isothermal models. The travel time decrease for the closed model is larger than that for the open model, reflecting the higher temperatures encountered by the stream traces. Overall, the differences between uncoupled and isothermal models are small, indicating that doing an uncoupled thermal analysis does not add much value compared to the previous isothermal analyses. Whether or not a fully coupled thermal analysis is valuable is addressed in Section 6.5 below.

Table 6.2. Performance measures for realization 1 of the open and closed versions of the new base case, for various thermal approaches.

\begin{tabular}{|c|c|c|c|c|}
\hline & $\begin{array}{l}\text { Path } \\
\text { length } \\
\text { (m) }\end{array}$ & $\begin{array}{c}\text { Travel } \\
\text { time } \\
\text { (yr) }\end{array}$ & $\begin{array}{c}\text { Average } \\
\text { Temperature } \\
\left({ }^{\circ} \mathrm{C}\right)\end{array}$ & $\begin{array}{c}\text { Velocity } \\
\text { (m/yr) }\end{array}$ \\
\hline \multicolumn{5}{|l|}{ Open Model } \\
\hline Isothermal & 1897 & 3.6 & 20 & 528 \\
\hline Uncoupled thermal and flow & 1886 & 2.9 & 27 & 643 \\
\hline Coupled thermal and flow & 1888 & 2.7 & 32 & 704 \\
\hline \multicolumn{5}{|l|}{ Closed Model } \\
\hline Isothermal & 2910 & 8.3 & 20 & 351 \\
\hline Uncoupled thermal and flow & 3218 & 6.0 & 36 & 532 \\
\hline Coupled thermal and flow & 3067 & 9.2 & 18 & 334 \\
\hline
\end{tabular}

\subsection{Review of natural convection theory for porous media}

Thermal convection in porous media can be divided into natural convection, in which fluid flow is driven by density differences arising from temperature differences, and forced convection, in which fluid flow is driven by head gradients arising from boundary conditions or source terms. If we want to use observed temperature profiles to infer information about regional groundwater flow conditions, we must ensure that natural convection is either negligible or properly accounted for. 
Whether or not natural convection occurs in a homogeneous medium of thickness L bounded above and below by constant temperatures $T_{0}$ and $T_{1}$ depends on the ratio of buoyancy forces to viscous forces, which is given by the Rayleigh number. If we approximate the temperature dependence of the density of water with a linear expression $\rho(T)=\rho_{0}\left[1-\beta\left(T-T_{\text {ref }}\right)\right]$ (Figure 6.2), then the Rayleigh number is given by

$$
R a=\frac{\beta K\left(T_{1}-T_{0}\right) L}{\left(\lambda / \rho_{0} c\right)},
$$

where $\mathrm{K}$ is hydraulic conductivity, $\lambda$ is thermal conductivity, and $\mathrm{c}$ is the specific heat of water. For an idealized system consisting of a laterally infinite medium, natural convection occurs if $R a$ exceeds the critical Rayleigh number given by (Lapwood, 1948)

$$
R a_{c}=4 \pi^{2} \approx 40 .
$$

Typical thermal properties for water-saturated granitic rock are $\beta=4 \cdot 10^{-4}{ }^{\circ} \mathrm{C}^{-1}, \lambda=2.6 \mathrm{~W} / \mathrm{m}^{\circ} \mathrm{C}$, $\rho_{0}=997 \mathrm{~kg} / \mathrm{m}^{3}$, and $\mathrm{c}=4,200 \mathrm{~J} / \mathrm{kg}^{\circ} \mathrm{C}$. Considering the upper $1,000 \mathrm{~m}$ of the model, where borehole observations exist, we take $\mathrm{K}=10^{-7} \mathrm{~m} / \mathrm{s}, \mathrm{L}=1,000 \mathrm{~m}$, and $\left(\mathrm{T}_{1}-\mathrm{T}_{0}\right)=20^{\circ} \mathrm{C}$, which yields $R a=1.3$, well below $R a_{\mathrm{c}}$. If we ignore the presumed decline in permeability toward the bottom of the model and consider the entire model thickness $\left(\mathrm{L}=3000,\left(\mathrm{~T}_{1}-\mathrm{T}_{0}\right)=60^{\circ} \mathrm{C}\right)$, we get $R a=12$, still below $R a_{\mathrm{c}}$. Thus, natural convection will not occur based on this idealized analysis. It has been recognized (Sorey, 1975) that some departures from ideality, such as temperatures that vary along the upper or lower boundary of the medium, make convection possible for all values of $R a>0$, as long as the temperature gradient exceeds the adiabatic gradient (Landau and Lifshitz, 1959):

$$
\frac{\partial T}{\partial z} \geq \frac{g T \beta}{c_{p}},
$$

where $c_{p}$ is water specific heat at constant pressure. Equation (6.5) is easily satisfied for our model, but Sorey (1975) also points out that for such small values of $R a$, natural convection is expected to have a negligible effect on the thermal and hydrologic regimes. The linear (i.e., conduction-dominated) shape of the deep portions of many of the observed temperature profiles supports the notion that natural convection does not play a significant role over the scale of the 4 $\mathrm{km}$ by $6 \mathrm{~km}$ model as a whole. However, it is possible that within localized areas of higher permeability (e.g., the high-K planes surrounding the Tsukiyoshi fault), natural convection may occur.

\subsection{1-D coupled thermal and flow analysis}

The basic interplay of convective heat flow accompanying infiltration or upward flow and conductive heat flow along the geothermal temperature gradient may be examined with a onedimensional (1-D) column model. An analytical solution is available for the simplest case in 
which thermal properties are assumed to be constant and flow is uniform from the top to the bottom of the column (to model infiltration). Here, we use a numerical model so that variable thermal properties can be accounted for, and more importantly, so that inflow and outflow at various depths can be considered.

The 1-D column model has the same grid spacing as the 3-D model, except that the top is at $\mathrm{z}=0$ masl and the bottom is at $\mathrm{z}=-3100 \mathrm{~m}$ (this shift is just for convenience, since the top elevation varies in the $3 \mathrm{D}$ model). Pressure and temperature are held constant at the top of the column at $\mathrm{T}$ $=15^{\circ} \mathrm{C}$ and $\mathrm{P}=1 \mathrm{~atm}$. A constant heat source of strength $0.0526 \mathrm{~W} / \mathrm{m}^{2}$ is placed at the bottom of the column, to drive the geothermal temperature gradient. This strength was chosen to give a conductive profile that matches (by eye) the deep linear parts (if any) of the observed T profiles shown in Figure 6.1. A thermal conductivity typical of granite, not specific to the Tono area, is used $\left(\lambda=2.6 \mathrm{~W} / \mathrm{m}^{\circ} \mathrm{C}\right)$. The model runs to steady state from an arbitrary starting condition, with heat flow and fluid flow fully coupled, so the resulting temperature versus depth profiles reflect a balance between conduction and convection.

\section{$\underline{\text { Alternative fluid flow scenarios }}$}

Modeled steady-state temperature profiles are shown in Figure 6.5 for four scenarios. For each scenario, we consider four fluid flow rates: 0 (conduction only), $1 \mathrm{~mm} / \mathrm{yr}, 10 \mathrm{~mm} / \mathrm{yr}$, and 20 $\mathrm{mm} / \mathrm{yr}$.

a) Inflow at the top with $\mathrm{T}=15^{\circ} \mathrm{C}$, outflow at the bottom. This scenario represents uniform infiltration throughout the model thickness. Whereas conductive heat transfer gives a straight $\mathrm{T}$ vs. $\mathrm{z}$ profile, convective profiles continuously curve.

b) Inflow at the top with $\mathrm{T}=15^{\circ} \mathrm{C}$, outflow partway down. This scenario represents shallow infiltration that does not extend over the entire model thickness. In a 3-D model, it could occur if vertical flow were intercepted by a sub-horizontal fracture zone or other relatively highpermeability layer that would promote lateral flow, or simply by a dipping lithologic contact in which a higher-permeability layer overlies a lower-permeability layer. The T vs. z profiles show a combination of a convective regime and a conductive regime, which many of the observed profiles seem to show.

c) Inflow partway down with $T$ equal to the ambient temperature at the inflow point (found by trial and error), outflow at the top. This scenario represents the same lithology as the preveious one, with the opposite flow direction. This signature is also commonly found in the observed data. If the inflow flow rate is large, a kink develops in the T vs. $\mathrm{z}$ profile, which may be what is seen in well MIU-2.

d) Inflow partway down with $\mathrm{T}=15^{\circ} \mathrm{C}$, outflow at the top. This scenario may not be too realistic as it is hard to envision how $15^{\circ} \mathrm{C}$ water would exist at depth, but the $\mathrm{T}$ vs. $\mathrm{z}$ profile shows a distinctive signature.

In regards to interpreting the field observations, the key features of the 1-d profiles are 
- A T vs. z profile that is concave up indicates downward flow.

- A T vs. z profile that is concave down indicates upward flow.

- A T vs. z profile that is linear indicates no flow.

- The deeper conductive part of a profile can be shifted (while maintaining its slope), as a result of overlying shallow convection. This may be why the deep parts of the observed profiles are offset from one another, although most show similar slopes.

\section{Comparison with field observations}

Assuming constant thermal conductivity, purely conductive profiles are linear, so any curve or kink in an observed T vs. z profile should represent fluid flow of some sort. However, it is worth noting the following points regarding interpretation of borehole temperature observations.

Thermal conductivity can vary with rock type. Thus, a conductive $T$ vs. $z$ profile can show a kink at a sharp lithological boundary or a curve at a gradational lithological boundary.

Depending on well completion techniques, fluid flow may occur in the borehole that is not representative of fluid flow in the surrounding rock. We expect that generally, the convective signatures of such flows will not be long lasting in space or time, because there is ample opportunity for heat transfer from the borehole to the surrounding rock to damp them out. However, borehole temperature measurements provide extremely sparse information in both space and time, making it generally quite difficult to distinguish local or transient events from global or steady ones a priori. This makes numerical simulation a valuable tool. If we cannot reproduce a given temperature fluctuation with any steady-state balance of fluid flow and conduction, chances are the observation represents a borehole effect or an instrument error.

Figure 6.6 shows all the observed temperature profiles. Each well or group of closely spaced wells is shown in a separate plot. The locations of the individual plots on the page roughly represent the wells' locations in space. Based on the maps of surface flow (Figures 4.2 and 4.3), we expect that in the northern, higher elevation portion of the model, downward fluid flow (scenario a or b above) prevails, whereas in the southern, lower elevation portion of the model, upward fluid flow (scenario c) prevails. Although there is a great deal of variability among the temperature profiles shown in Figure 6.6, this flow pattern is generally supported. Ignoring sharply changing temperatures in the upper 10-20 m, wells that suggest evidence of downward fluid flow are MIU-3, DH-5, DH-6, DH-7, DH-8 (above $700 \mathrm{~m}$ ), and one of the two DH-11 profiles. Wells that suggest upward flow are MIU-2, AN-1, DH-2, and DH-3. Localized temperature peaks, such as those shown for wells MIU-1, DH-2, DH-4, and DH-9 suggest horizontal flow across the borehole, which requires a 3-D model to address.

Figure 6.6 includes several instances in which temperature measurements were repeated after several months or years. In wells DH-3, DH-6, and DH-7 temperature profiles show a small, 
roughly uniform offset, suggesting calibration changes between measurements. This should pose no real problem to analysis - if need be, the average of the two profiles could be used. For wells DH-2 and DH-11 the differences between profiles are much larger and harder to explain. They could possibly represent transient effects or more severe instrument problems. Without additional, independent information it is difficult to be sure which.

\subsection{3-D coupled thermal and flow analysis}

For the fully coupled thermal and flow analysis, we specify the same linear initial temperature distribution as for the uncoupled analysis, but allow the both the temperature and head distributions to change as the system evolves to a steady state, as was done for the 1-D model.

Table 6.1 compares the water budgets for the fully coupled, uncoupled, and isothermal approaches. Differences among the different thermal approaches are small compared to differences between the open and closed boundary conditions.

The steady-state temperature distributions and stream traces are shown in Figures 6.7 and 6.8, for the open and closed models, respectively. The temperature distributions differ markedly from the initial linear temperature distribution that represents a purely conductive temperature regime, implying that convective transport accompanying fluid flow is significant. Comparing stream traces and temperature distributions illustrates how convection occurs. For the open model, flow is mainly up and out of the southern half of the model, and the temperature distribution reflects this by showing higher temperatures at shallow depths resulting from the upward flow of deeper, hotter water (compare Figures 6.3 and 6.7). For the closed model, flow is mainly down through the model surface, and the temperature distribution shows greatly lowered temperatures over most of the model resulting from the infiltration of cool surface water (compare Figures 6.4 and $6.8)$.

Table 6.2 compares average performance measures for one realization of the coupled thermal models with the corresponding realization for the uncoupled thermal and flow models and the isothermal flow models. The open model measures do not change much between uncoupled and coupled models: path length is essentially the same and travel time decreases from 2.9 to 2.7 years. The closed model measures change a little more: path lengths are a little shorter but travel time increases from 6.0 years for the uncoupled model to 9.2 years for the coupled model, indicating a much slower average velocity. This velocity decline is due to the much cooler temperatures present in the coupled model, with their correspondingly higher viscosities. In terms of predicting performance measures, the tentative conclusion from Section 6.2 that the isothermal models are adequate remains valid.

Figure 6.9 shows temperature versus depth profiles extracted from the steady-state 3-D model results. Open-model profiles show subtle departures from linearity, indicating a relatively small convective contribution. In contrast, close-model profiles are dominated by cool-water recharge down to elevations of -1500 masl. Compared to the field observations shown in Figure 6.6, it is clear that the open model is much better than the closed model at capturing the character of the field data. This is a significant finding, because the isothermal steady-state and transient 
modeling results described in Sections 4 and 5 did not produce distinct results that could be compared to field data, precluding us from picking a preferred model.

One important caveat about the model is worth mentioning. The open lateral boundary conditions maintain the initial linear temperature and head profiles. That is, they consider a conductive temperature profile and hydrostatic pressures. This would be a good choice if we felt that it were justified based on the topography and regional hydrology, which may not be the case for the present studies. A better approach would be to use the present results as the first step in an iterative process. We could assign steady-state temperature and head values representing convection (from an appropriate location near the middle of the model) at the lateral boundaries for a second simulation. This process could be repeated until the resulting temperature and head distribution did not change significantly. Another alternative would be to create a much larger model, so the lateral boundaries do not come into play.

\section{Summary, Conclusions, and Future Directions}

\subsection{Summary}

We have extended our previous studies of the Tono area by considering a new base case. The main differences from the old case are primarily open lateral boundaries, a more elaborate Tsukiyoshi fault representation with a high-permeability 'sandwich' surrounding a lowpermeability core, and a higher porosity for the sedimentary rocks overlying the fractured granitic basement. The open lateral boundary conditions have a marked effect on the regional groundwater flow pattern. With closed lateral boundaries, the net surface flow is into the model, representing recharge of precipitation. With open lateral boundaries, the net surface flow is out of the model, representing spring discharge and conversion of groundwater to river flow. Travel times and path lengths from the specified release points to the model boundary are somewhat shorter for the open model, as more stream traces exit the model through the surface. The new Tsukiyoshi fault representation has only a modest effect on the groundwater flow pattern. The higher sedimentary rock porosity has very little effect because only a few of the stream traces encounter sedimentary rock.

In addition to calculating steady-state flow fields, the new base case was used to simulate the transient response to the Long Term Pump Test (LTPT). Significant differences in pressure transients were found for pumping intervals above and below the Tsukiyoshi fault, confirming that the fault is an important hydrologic component of the model. Because the pumping rate during the test is small compared to inflow and outflow through model boundaries, the choice of lateral boundary conditions has little effect on the pressure transients in observation wells.

Thermal effects on the hydrologic model were studied by allowing temperature to vary in the model. First, an examination of observed borehole temperature profiles suggests that conduction and convection are both important heat flow mechanisms. Next, an uncoupled thermal and flow analysis was done to examine the effect of using temperature-dependent hydrologic properties along with a linear temperature profile, without letting the resulting flow field alter the temperature distribution. Performance measures were little changed. One-dimensional column 
studies were then used to characterize the signatures of different combinations of heat and fluid flow for fully coupled thermal and flow analysis. Several features noted in the observed temperature profiles were analyzed. Finally, fully coupled thermal and flow simulation using the 3-D model were done. Steady-state temperature distributions were strongly affected by the different flow patterns of the open and closed models, and the closed model temperature profiles do not resemble observed profiles nearly as well as do the open model profiles. Interestingly, the isothermal and fully coupled thermal models produce similar performance measures for path length and travel time, suggesting that the use of isothermal models for such purposes is adequate.

\subsection{Conclusions}

We began this study with two versions of the new base case model: one with mainly open lateral boundaries and the other with mainly closed lateral boundaries. Although they produce similar performance measures for both steady-state flow (path length and travel time for stream traces leaving release points) and transient flow (timing and magnitude of pressure changes at observation wells), they predict quite different overall groundwater flow patterns. We would like to use observed data to decide which model is a better representation of reality. Three types of analyses were conducted: steady-state isothermal flow, transient isothermal flow, and steadystate non-isothermal flow.

For steady-state isothermal flow, the only observed data with which to compare is surface recharge data. The closed model compares better with this data, showing net surface recharge rather than the net surface discharge predicted by the open model. However, the observed data does not provide good coverage of the model as a whole, and may relate more to shallow hydrology within the sedimentary rocks than to large-scale groundwater flow through the deeper granitic basement. We believe that steady-state isothermal analysis cannot be used to pick a preferred model.

For transient isothermal flow (well-test analysis of the LTPT), pressure changes at observation locations close to the pumping well are not very sensitive to the lateral boundary conditions. Pressure responses closer to the model boundaries are so small that differences reflecting the different boundaries probably would not be observable under real field conditions. Therefore, we believe that pressure-transient analysis cannot discriminate between the two models either.

In contrast, for steady-state fully coupled thermal and flow analysis, the two models predict strongly different temperature versus depth profiles, and numerous measurements from the field agree better with the open model. We believe that based on this data we can eliminate from consideration the closed model with its large infiltration rates that produce widespread deep recharge. Deep recharge of cool surface water creates temperature profiles strongly at odds with observed profiles.

A model with closed lateral boundaries would be possible if recharge were confined to shallow sediments and did not penetrate very far into the granitic basement. Given the sparse surface recharge data, which suggests that net surface recharge is in fact more likely than net surface 
discharge, such a model could be an improvement over the current open model. One possible way to achieve such a groundwater flow pattern would be to significantly increase the permeabilities of the sedimentary rocks above those of the granitic rocks. Then surface infiltration would flow vertically in the sedimentary rocks, then sub-horizontally, downgradient (mainly from west to east) at the interface between the sedimentary rocks and the underlying granite. Very few measurements of the hydrologic properties of the sedimentary rocks are currently available, and it would therefore be worthwhile to conduct further field tests to try to better ascertain their characteristics.

In summary, careful thought is required in order to choose appropriate boundary conditions for a large model such as the present one, in which surface effects may or may not be significant at great depths.

\subsection{Future Directions}

Our work so far suggests that both further model development and further field characterization studies would be helpful for improving our representation of subsurface flow and transport.

To better characterize the regional water budget, in particular the role of the shallow sedimentary layers in connecting surface infiltration and the underlying granitic basement, the following data would be useful:

- The hydrologic character of the sedimentary layers (i.e., is flow fracture-dominated?); hydraulic conductivity and porosity values for sedimentary rocks

- Recharge estimates over a wider area (quantitative or qualitative information)

- Flow data for the Toki and Hiyoshi rivers

- Information on any big contributors to the regional water budget (e.g., agricultural or recreational uses)

The role of the Tsukiyoshi fault has been shown to be significant. Further pumping tests making use of wells crossing the fault would be valuable. In particular, the large response that occurred when Well MIU-2 packers were removed prior to the LTPT could possibly be modeled in order to study near-fault properties.

The conclusion from the previous stage of the Tono area modeling that effective fracture porosity is one of the most uncertain model parameters is still valid. Therefore, we believe that efforts should be taken to improve understanding of effective fracture porosity. One possibility would be to use the specific storage obtained from well-test analysis to learn about storage capacity for transport. Other means would be to run tracer tests or to examine natural tracers on a basin wide scale, to attempt to get at groundwater residence times, from which constraints on effective porosity may be found. 


\section{Acknowledgments}

This work was supported by Japan Nuclear Fuel Cycle Corporation (JNC) and Taisei Corporation of Japan through the U.S. Department of Energy Contract No. DE-AC0376SF00098. We are particularly indebted to A. Sawada of JNC and Y. Ijiri of Taisei Corp. for useful discussions. We would also like to thank S. Takeuci and H. Saegusa for making various field data available to us. The authors would like to thank S. Finsterle and K. Ito for their critical review.

\section{References}

Doughty, C. and K. Karasaki, Using an effective continuum model for flow and transport in fractured rock: The H-12 flow comparison, Rep. LBNL-44966, Lawrence Berkeley National Lab., Berkeley, Calif., 1999.

Doughty, C. and K. Karasaki, Evaluation of uncertainties due to hydrogeological modeling and groundwater flow analysis: Effective continuum model using TOUGH2, Rep. LBNL-48151, Lawrence Berkeley National Lab., Berkeley, Calif., 2001.

Hillel, D., Fundamentals of Soil Physics, Academic Press, Orlando, Florida, 413 p., 1980.

Karasaki, K., Well test analysis in fractured media, Ph.D. thesis, Department of Material Science and Mineral Engineering, University of Calif., Berkeley, Rep. LBL-21442, Lawrence Berkeley National Lab., Berkeley, Calif, 1987.

Landau, L.D. and E.M. Lifshitz, Fluid Mechanics, Pergamon Press, London, 1959.

Lapwood, E.R., Convection of a fluid in a porous medium, Proc. Cambridge Phil. Soc., 44, 508$521,1948$.

National Research Council Committee on Fracture Characterization and Fluid Flow, Rock fractures and fluid flow: contemporary understanding and applications, National Academy Press, Washington, D.C., 1996.

Oyamada, K. and T. Ikeda, Uncertainty analysis on hydrologic modeling in heterogeneous media (CORE Collaborative Study), Japan Nuclear Fuel Cycle Development Institute TJ1400 99-023, 1999.

Peaceman, D.W., Interpretation of well-block pressures in numerical reservoir simulation, Society of Petroleum Engineers Journal, 18(3), 183-194, 1978.

Pruess, K., C.M. Oldenburg, and G.J. Moridis, TOUGH2 User's Guide, Version 2.0, Rep. LBNL43134, Lawrence Berkeley National Lab., Berkeley, Calif., 1999.

Sawada, A., H. Saegusa, S. Takeuchi, K.Nakano, and Y. Ijiri, Evaluation of Uncertainties due to Hydrogeological Modeling and Groundwater Flow Analysis, in proceedings, Symposium on flow problems in fractured rocks, Japanese Geotechnical Society, September, 2001. 
Sawada, A., H. Saegusa, K. Nakano, and H. Osawa, A study of uncertainties for evaluating groundwater flow by multiple modeling approaches, in proceedings, $32^{\text {nd }}$ Japanese Rock Mechanics Symposium, Tokyo, 2003.

Sorey, M.L., Numerical modeling of liquid geothermal systems, Ph.D. dissertation, Dept. of Civil Engineering, University of California, Berkeley, 65 pp., 1975.

Takeuchi, S., M. Shimo, N. Nishijima, and K. Goto, Investigation of hydraulic properties near the fault by pressure interference test using $1000 \mathrm{~m}$ depth boreholes, The $31^{\text {st }}$ Japanese Rock Mechanics Symposium, pp. 296-300, 2001.

Thiem, G., Hydrologische Methoden, J.M. Gebhardt, Leipzig, 1906. 


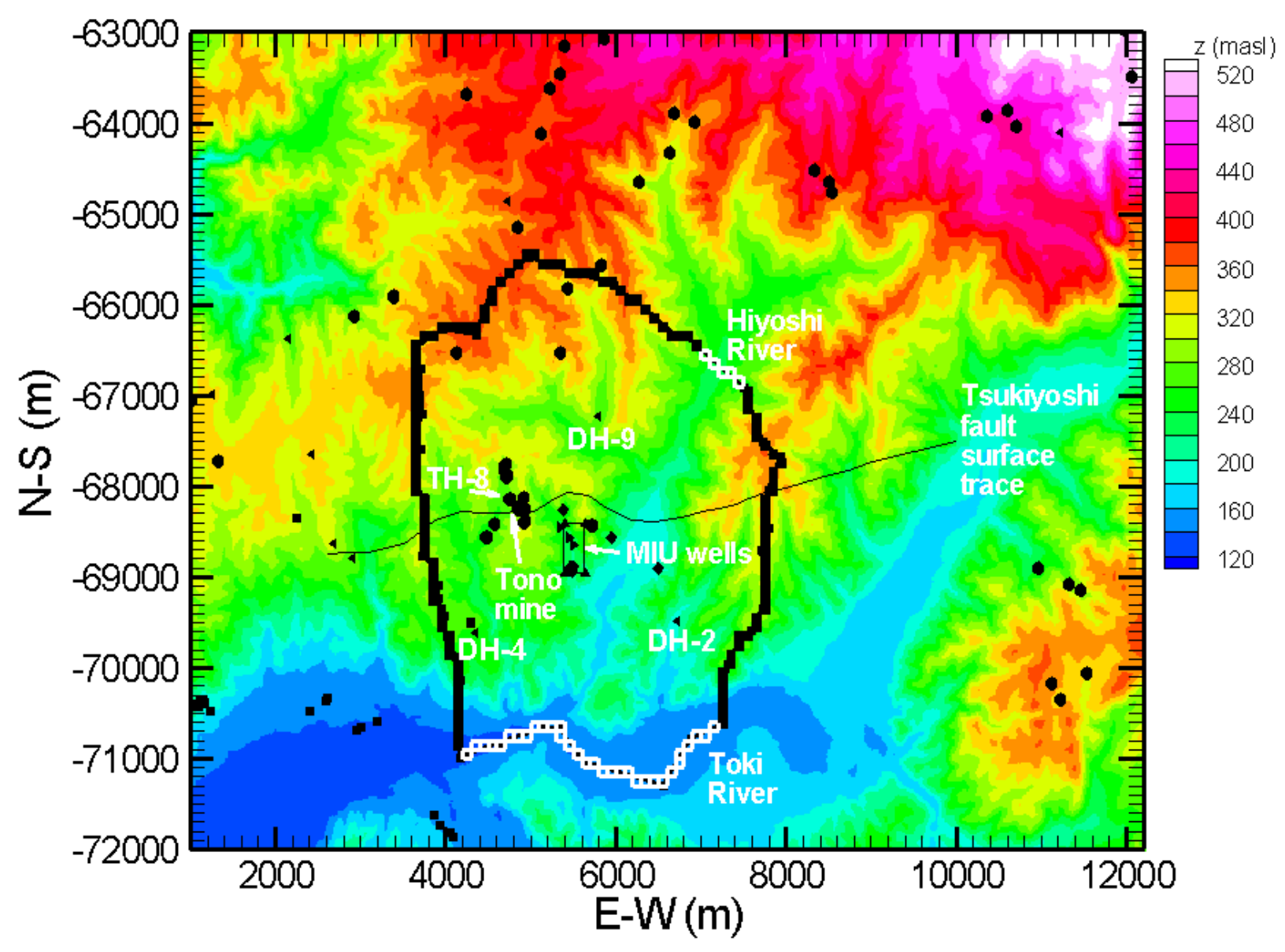

Figure 2.1. Surface elevations, lateral model boundary, and features of interest for the $4 \mathrm{~km}$ by 6 $\mathrm{km}$ model of the Tono region. For previous studies and the new base-case closed model, the black boundary is closed and white is open (constant head). For the new base-case open model, all lateral boundaries are open except below the Toki River (the southern model boundary), which is closed. 

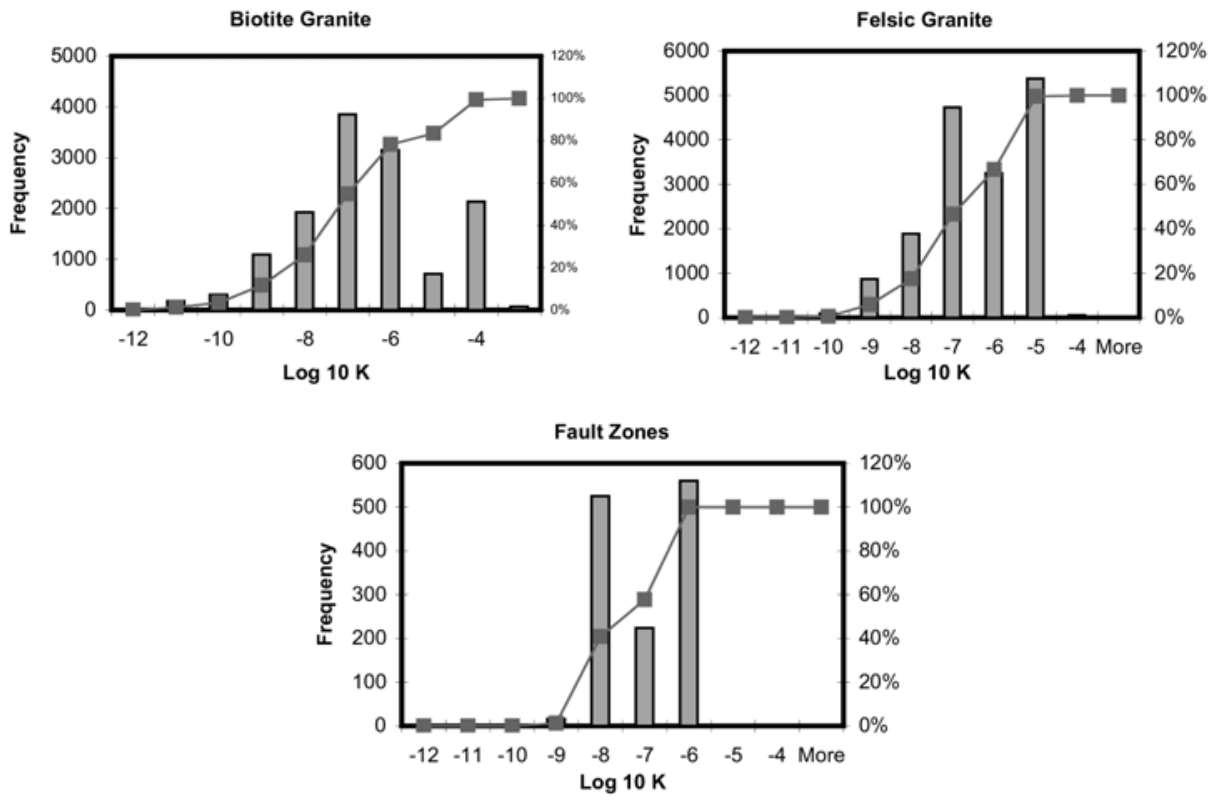

Figure 2.2. Distributions of $\log _{10} K$ obtained from slug tests and pumping tests. Each conductivity value is weighted by the length of test interval; frequency shows the number of grid blocks that are assigned a conductivity in the corresponding range. The line shows the cumulative distribution function. 


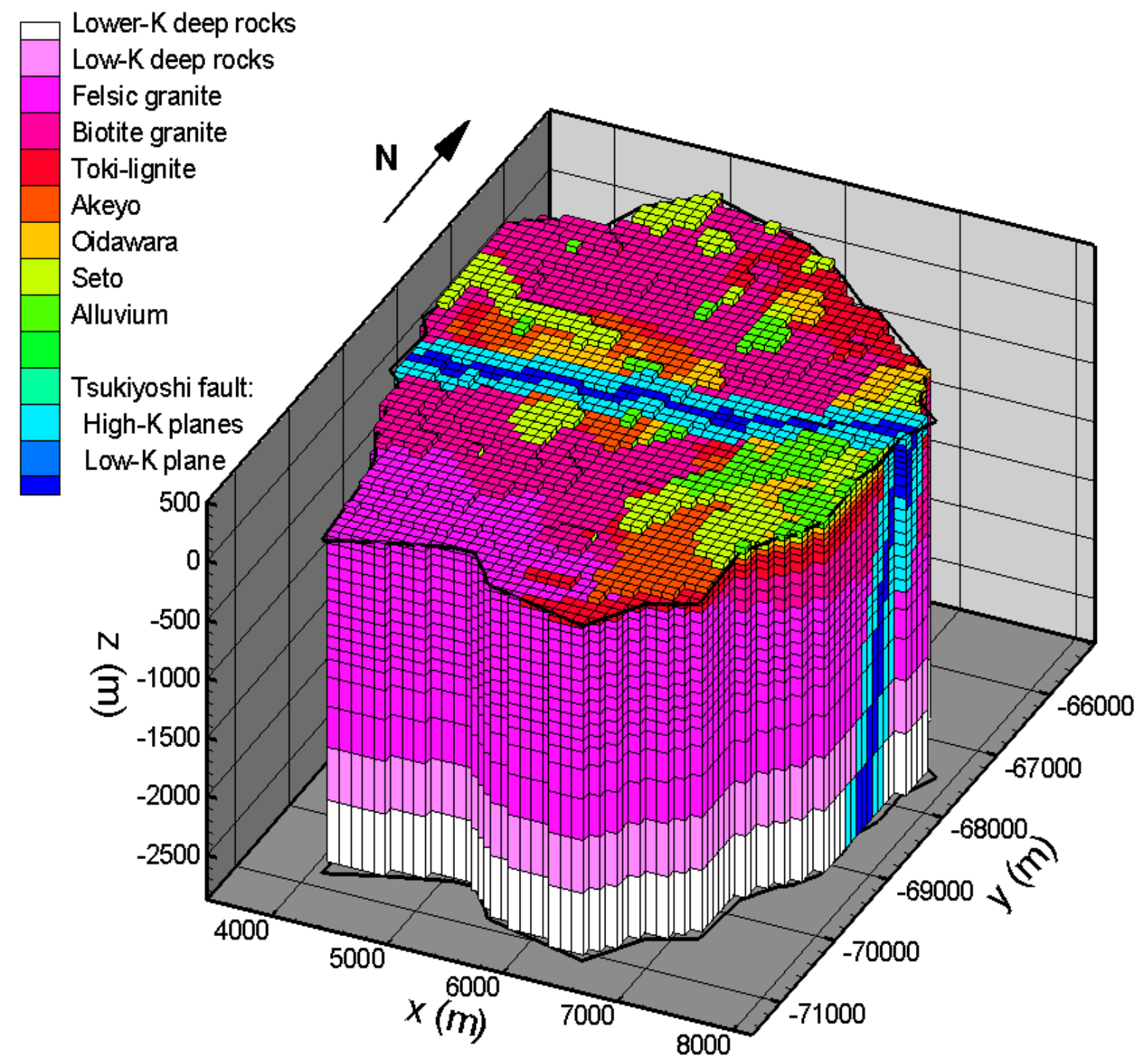

Figure 3.1. Perspective view of the new base-case model showing different materials. Within each material, permeability and porosity are drawn from stochastic distributions. 

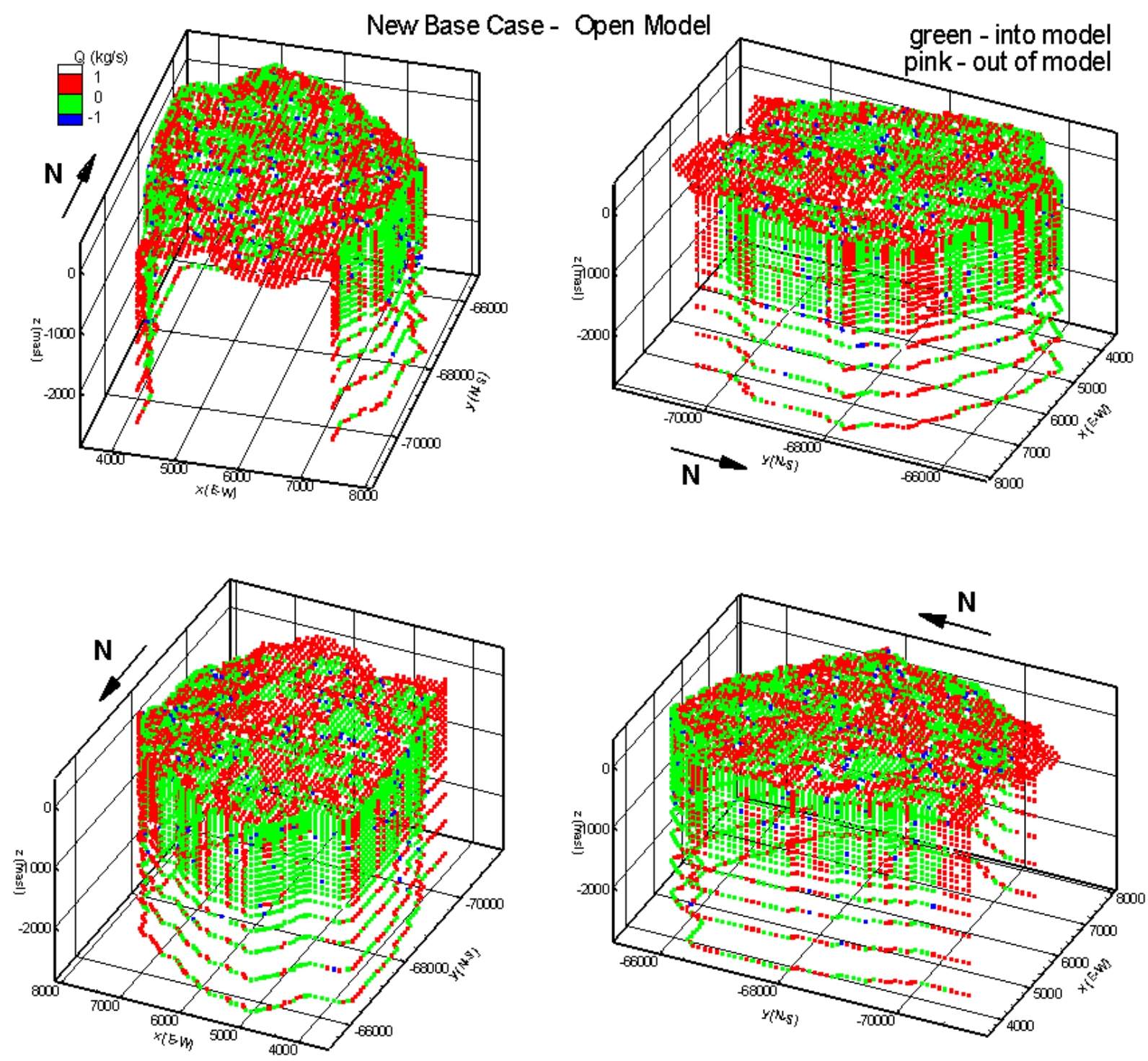

Figure 4.1. Lateral flows in and out of the model for the new base case - open model. Positive flow rates are discharge out of the model, negative flow rates are recharge into the model. 


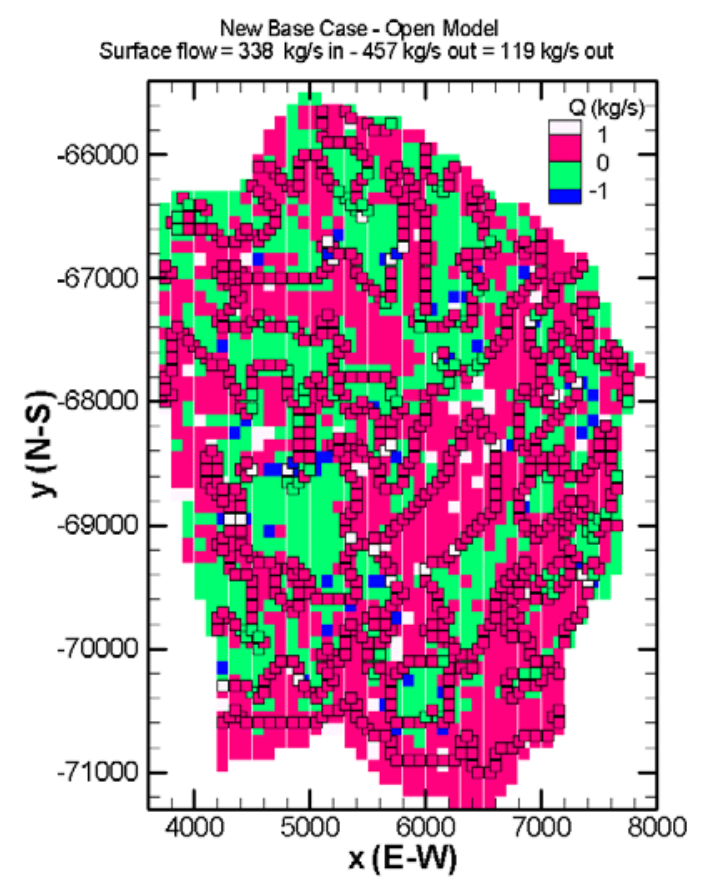

Figure 4.2. Mass flow distribution through the top surface of the model for the new base case open model, realization 1. Positive flow rates are discharge out of the model, negative flow rates are recharge into the model.

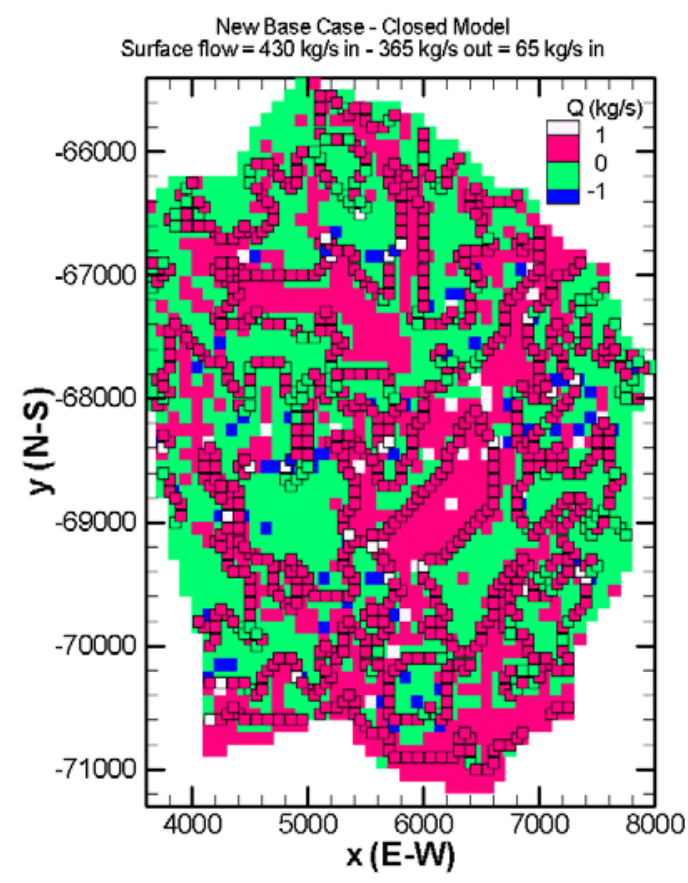

Figure 4.3. Mass flow distribution through the top surface of the model for the new base case closed model, realization 1. Positive flow rates are discharge out of the model, negative flow rates are recharge into the model. 


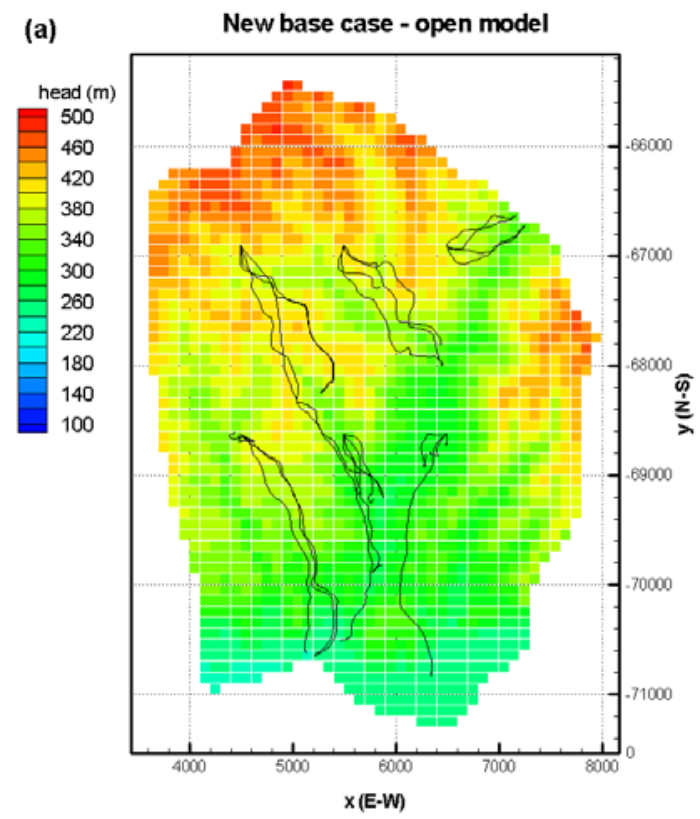

(b)

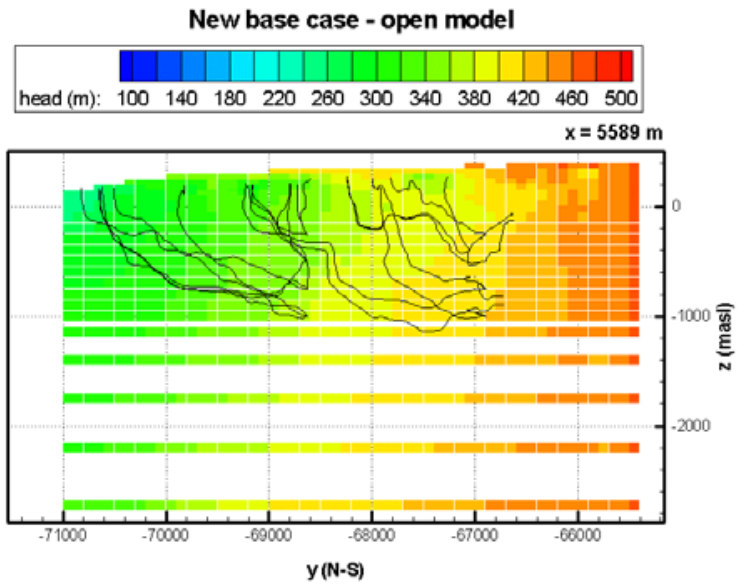

Figure 4.4. All stream traces leaving the 24 release points projected onto (a) the top surface of the model, and (b) a vertical cross-section near the center of the model, for the new base case open model, realization 1. The steady-state head distribution on the projection surface is also shown.
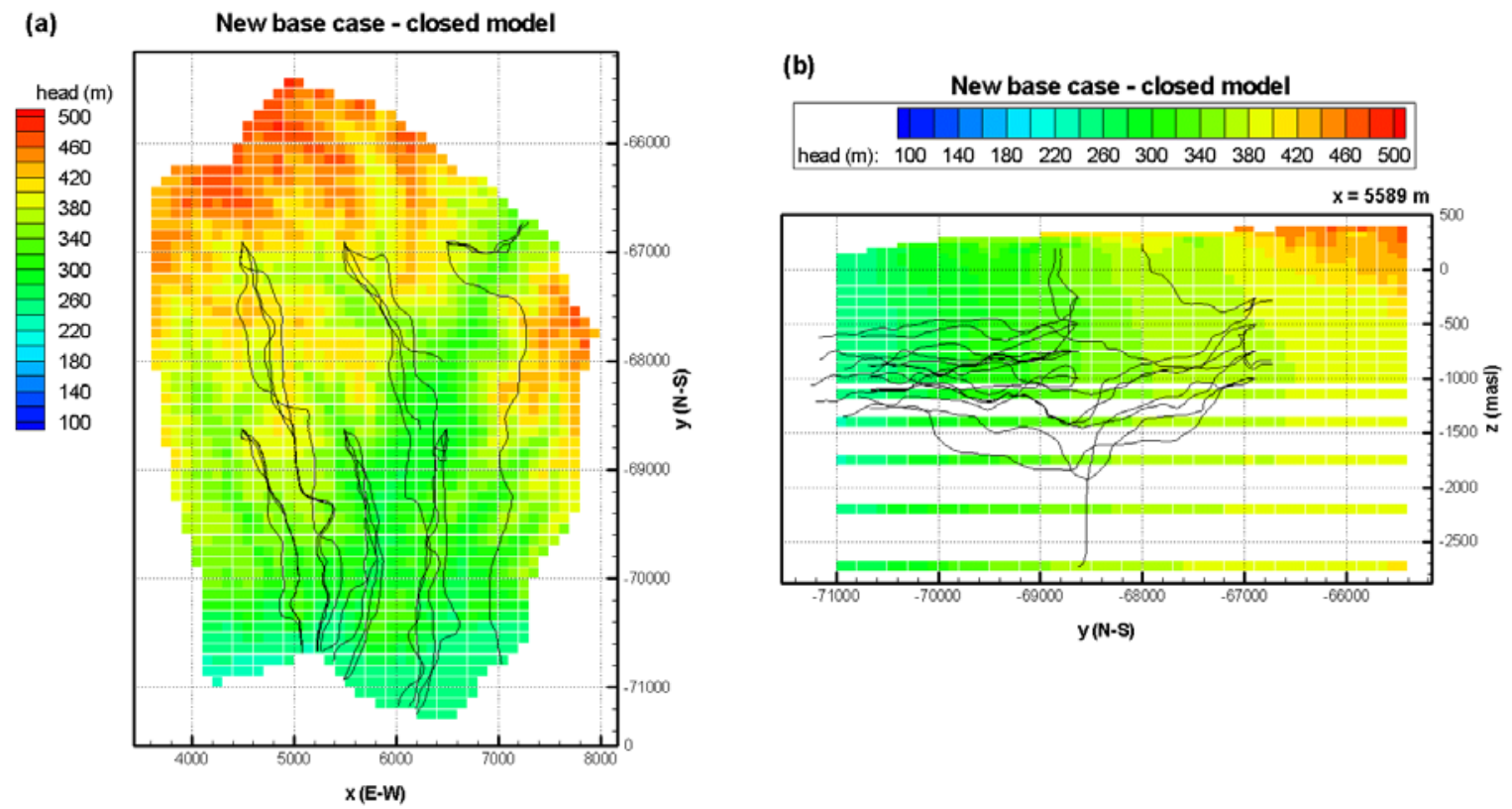

Figure 4.5. All stream traces leaving the 24 release points projected onto (a) the top surface of the model, and (b) a vertical cross-section near the center of the model, for the new base case closed model, realization 1 . The steady-state head distribution on the projection surface is also shown. 

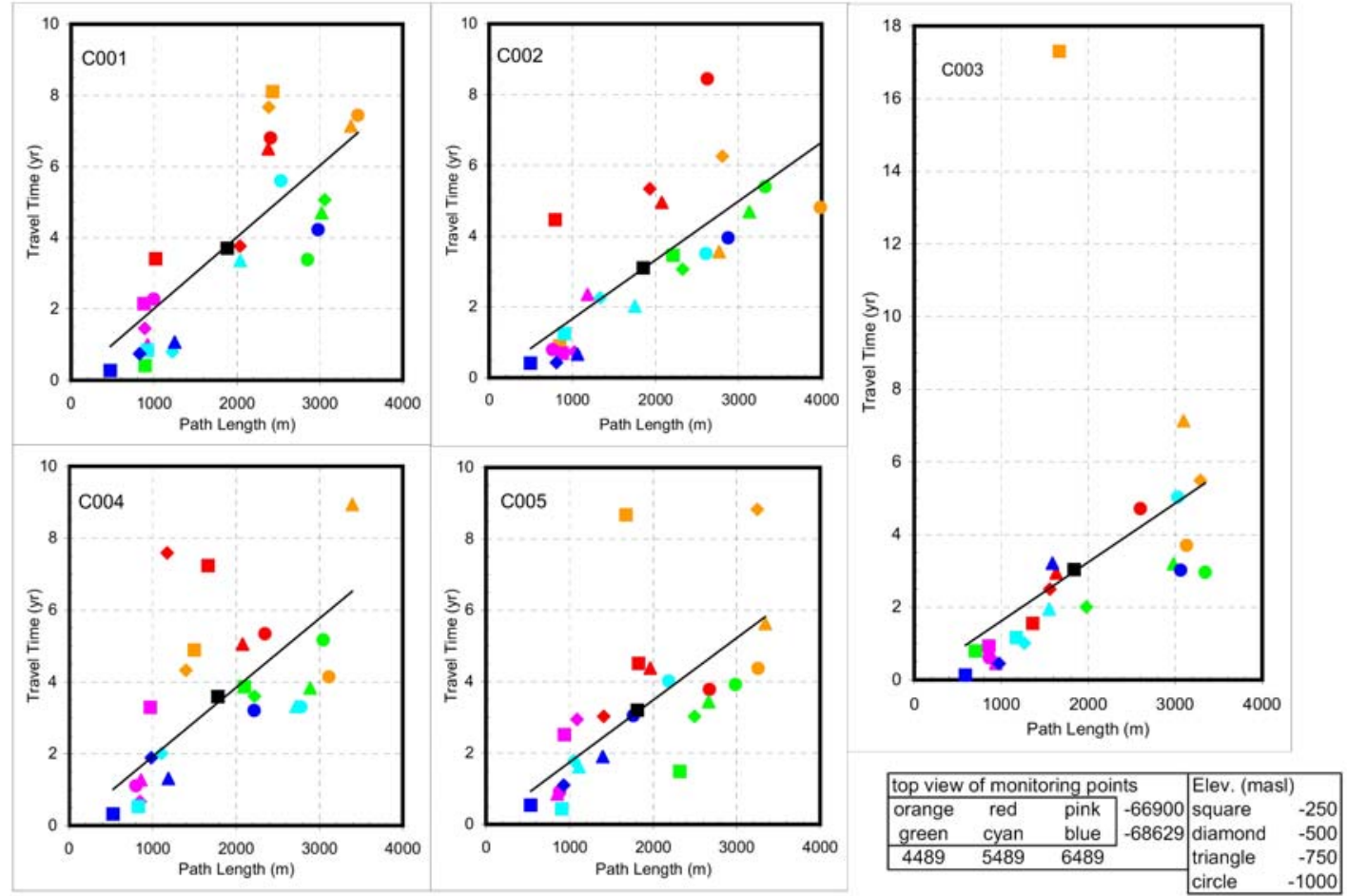

Figure 4.6. Travel time versus path length for all release points for five realizations of the new base case - open model. Symbol color and shape identify the release point $(\mathrm{x}, \mathrm{y})$ location and $(\mathrm{z})$ elevation, respectively. 

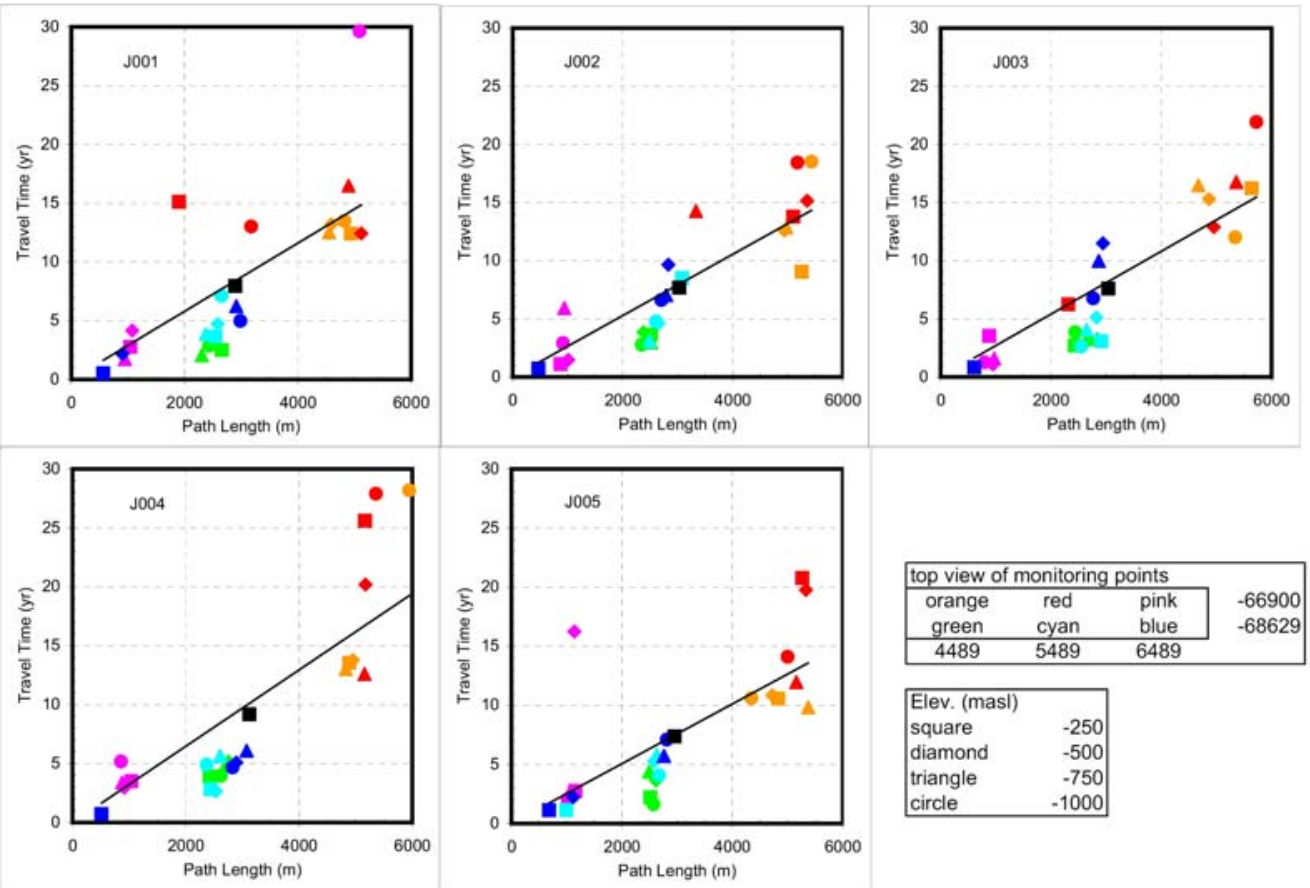

Figure 4.7. Travel time versus path length for all release points for five realizations of the new base case - closed model. Symbol color and shape identify the release point $(\mathrm{x}, \mathrm{y})$ location and (z) elevation, respectively. 


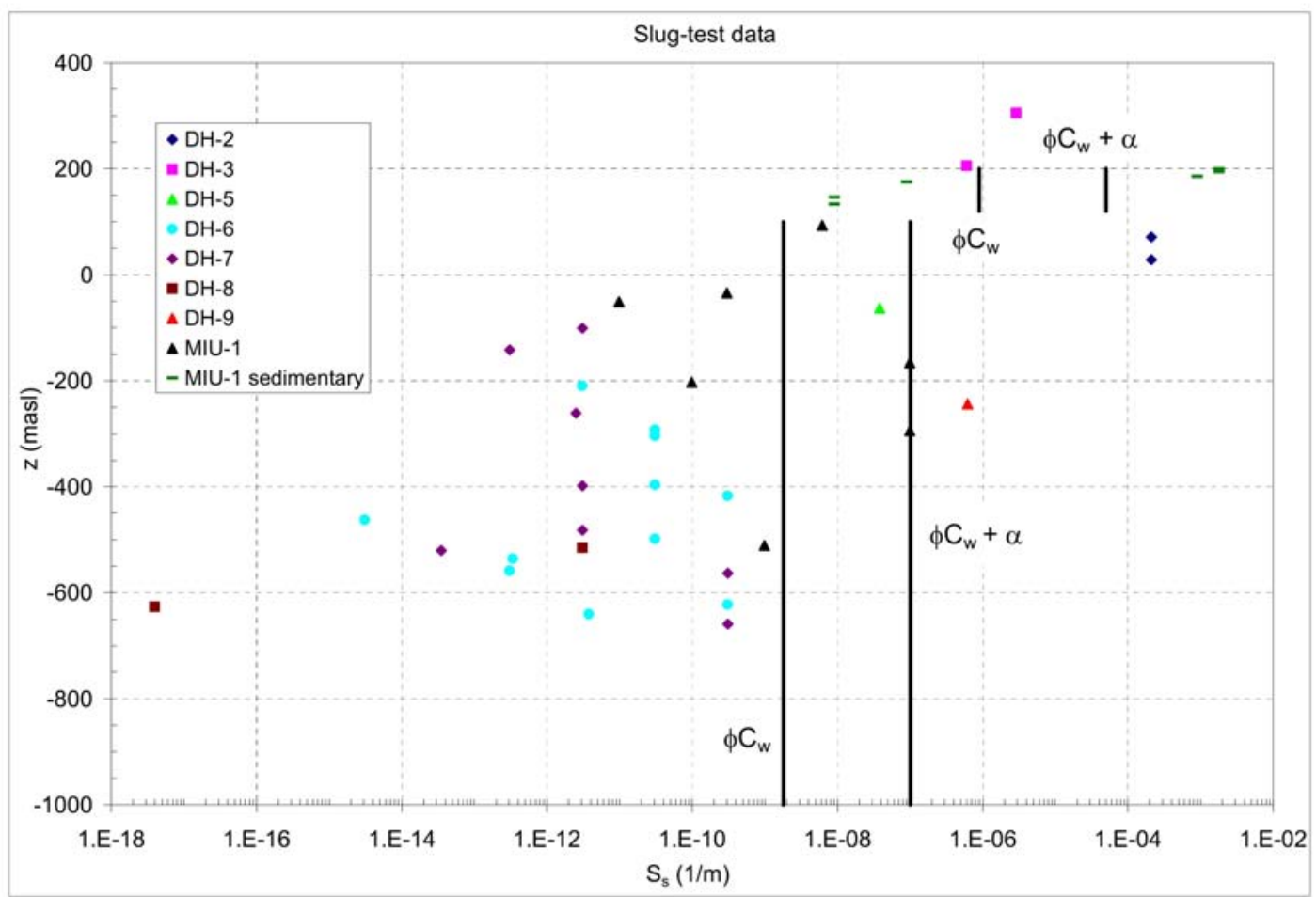

Figure 5.1. Specific storage values inferred from slug tests (symbols) and theoretical values (lines) for granite (elevations below 100 masl) and sedimentary rocks (elevations above 100 masl), assuming $\alpha=9.8 \cdot 10^{-8} 1 / \mathrm{m}$ for granitic rocks and $\alpha=5 \cdot 10^{-5} 1 / \mathrm{m}$ for sedimentary rocks. 

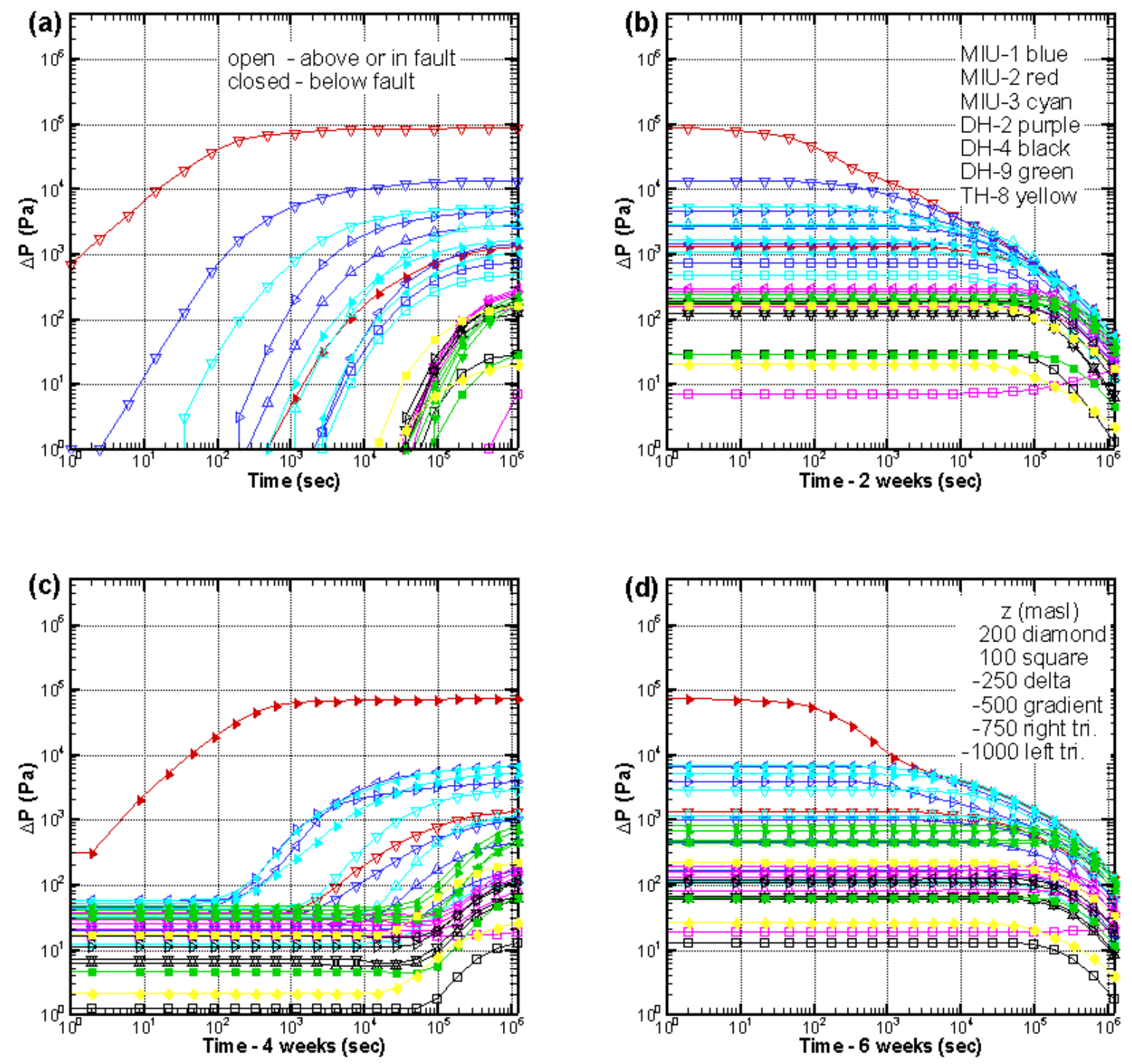

Figure 5.2. Modeled pressure transients for the open version of the new base case during the LTPT, realization 1: (a) upper interval pumps, (b) rest, (c) lower interval pumps, (d) rest. 


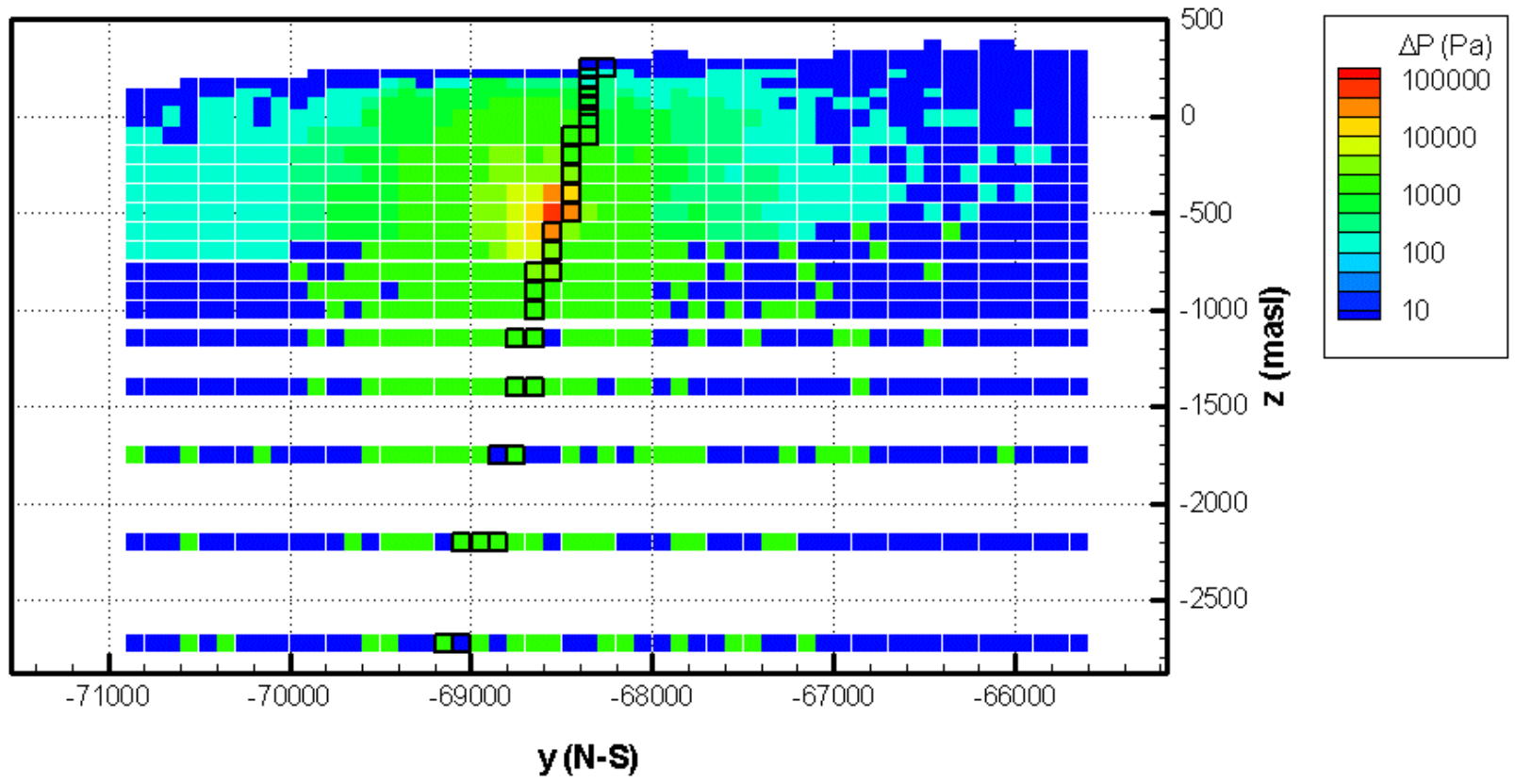

(b)

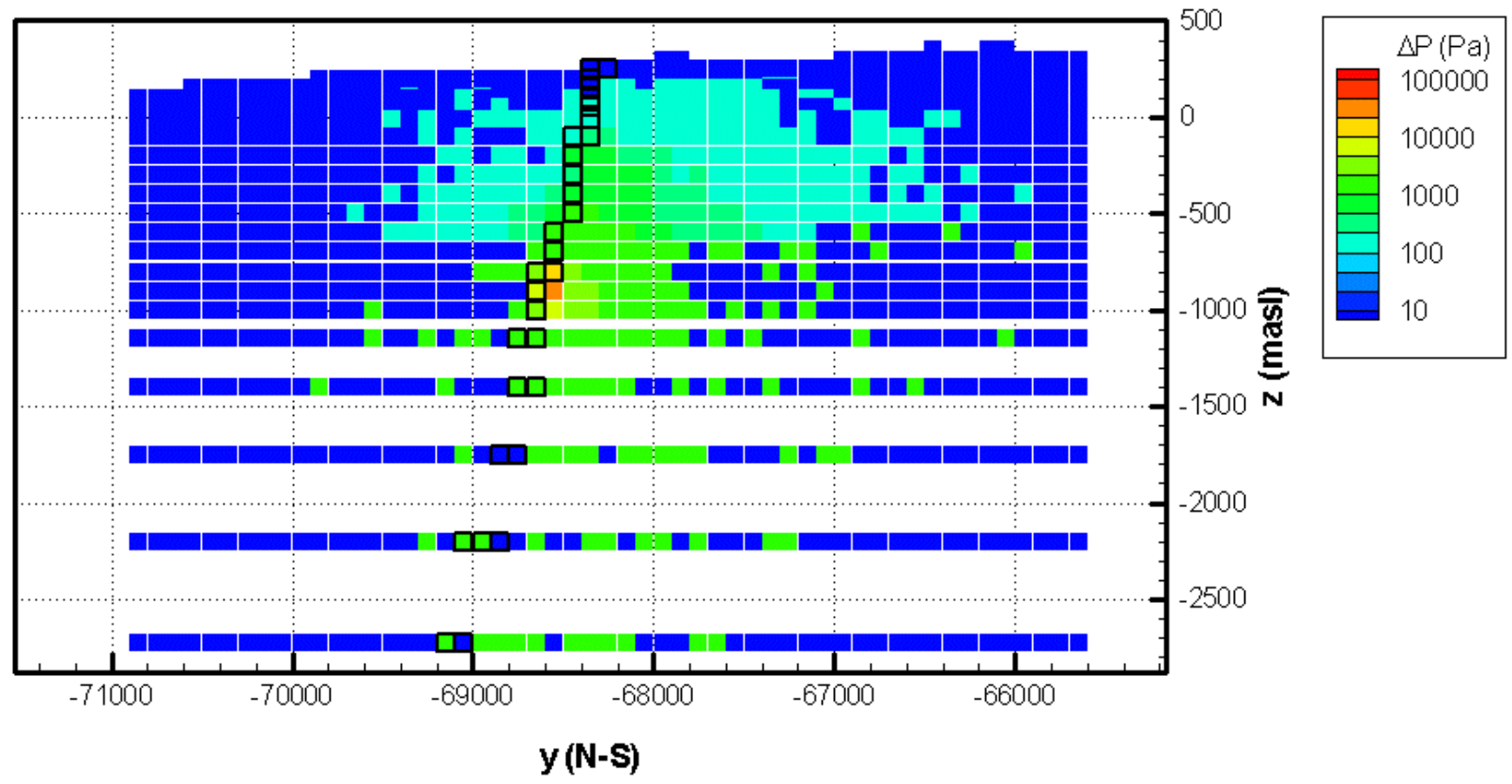

Figure 5.3. Modeled drawdown at the end of the pumping periods for the (a) upper and (b) lower pumping intervals in Well MIU-2. The grid blocks outlined in black represent the lowpermeability plane of the Tsukiyoshi fault. The $y-z$ cross-section shown passes through the modeled location of well MIU-2. 

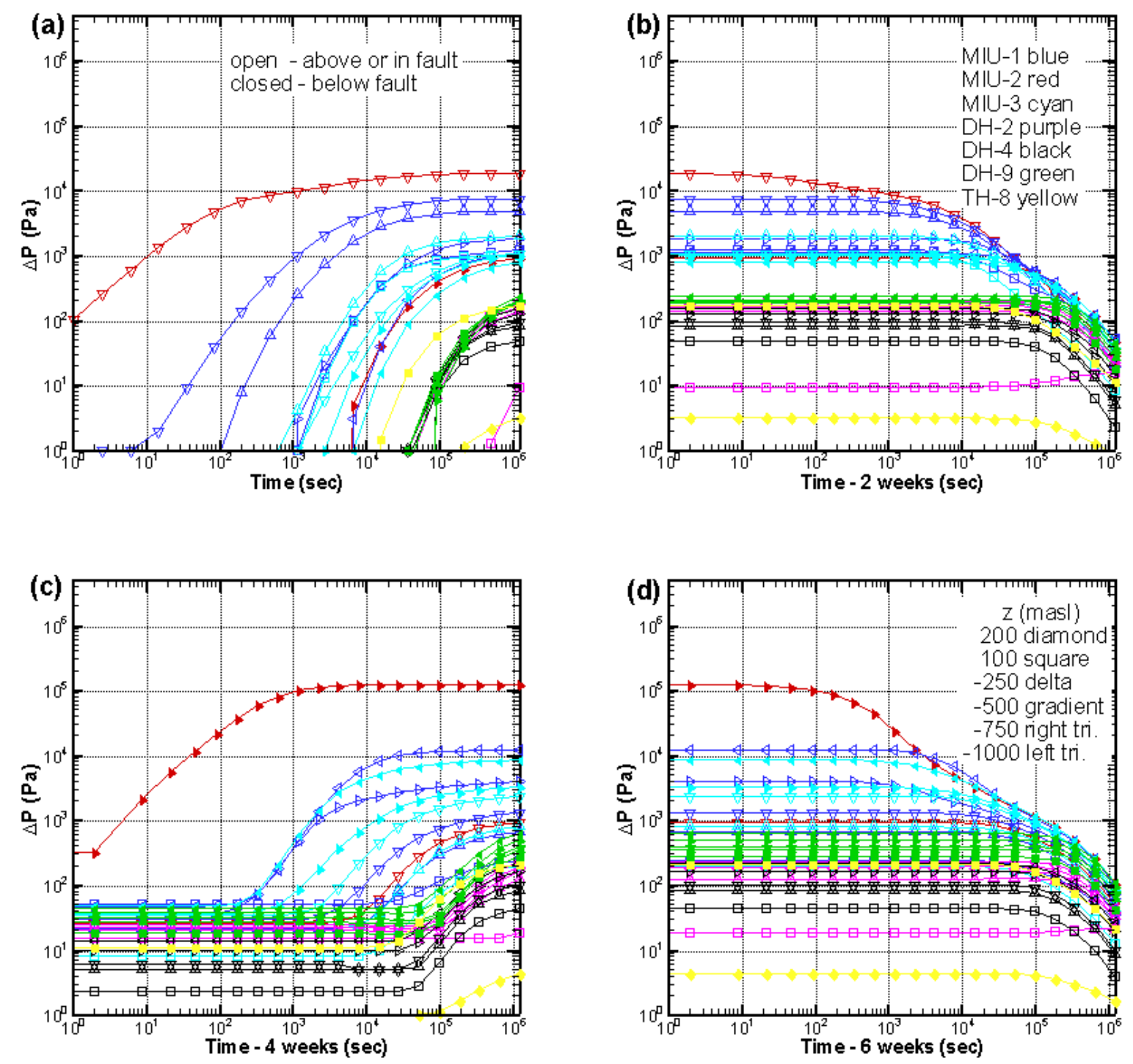

Figure 5.4. Modeled pressure transients for the open version of the new base case during the LTPT, realization 2: (a) upper interval pumps, (b) rest, (c) lower interval pumps, (d) rest. 

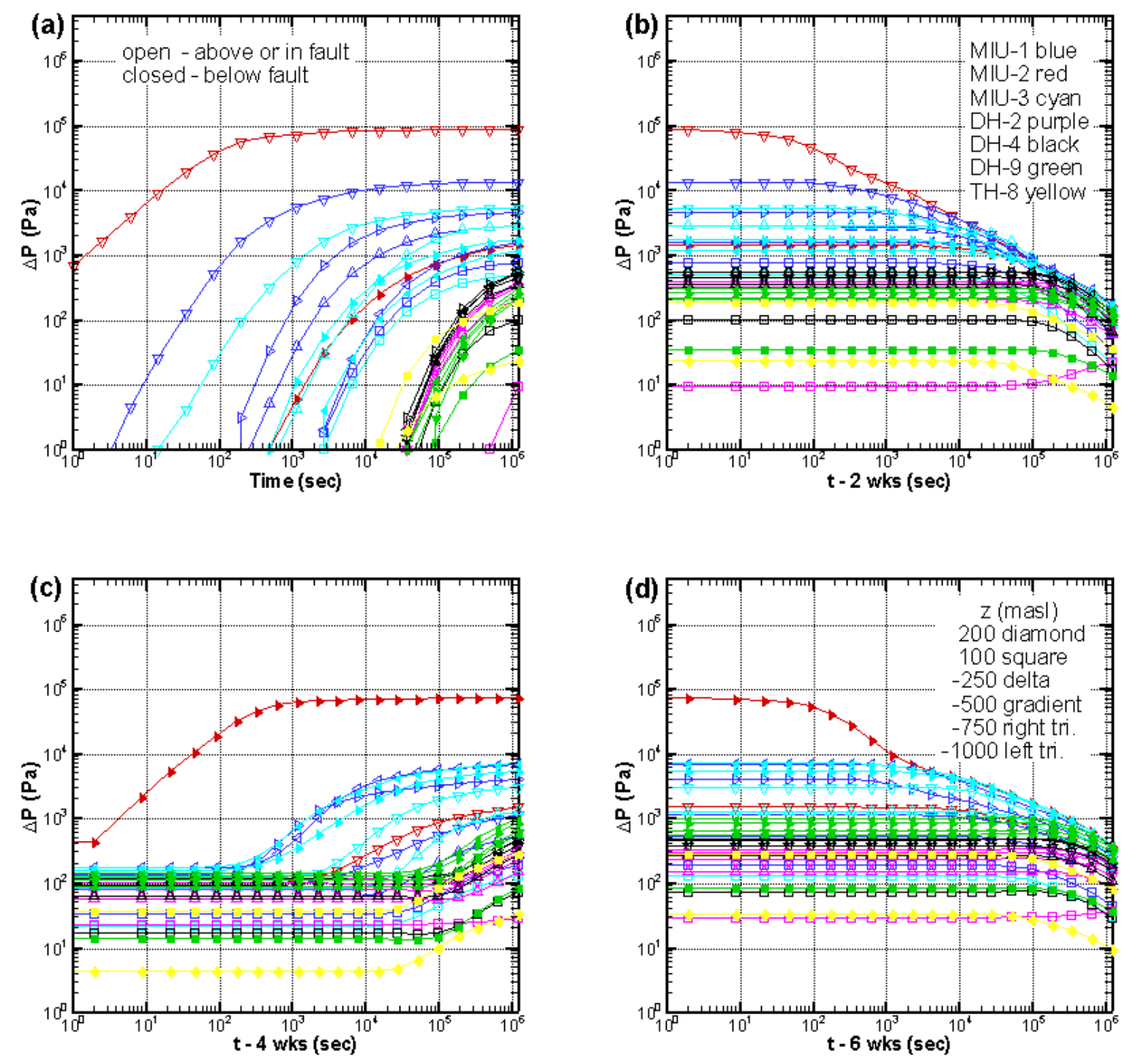

Figure 5.5. Modeled pressure transients for the closed version of the new base case during the LTPT, realization 1: (a) upper interval pumps, (b) rest, (c) lower interval pumps, (d) rest. 

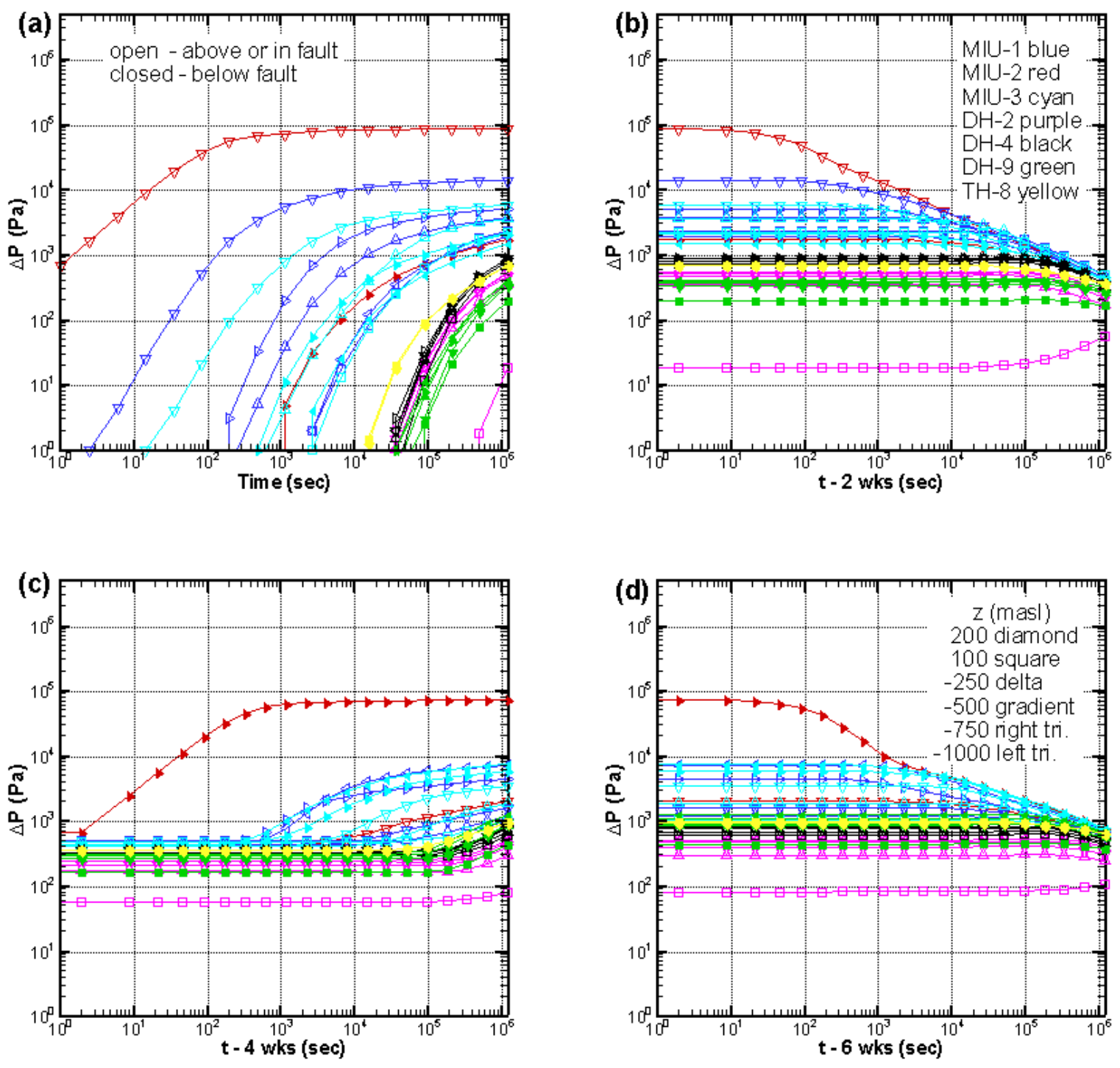

Figure 5.6. Modeled pressure transients during the LTPT for the closed version of the new base case with constant-flux boundary conditions at the ground surface, realization 1: (a) upper interval pumps, (b) rest, (c) lower interval pumps, (d) rest. 


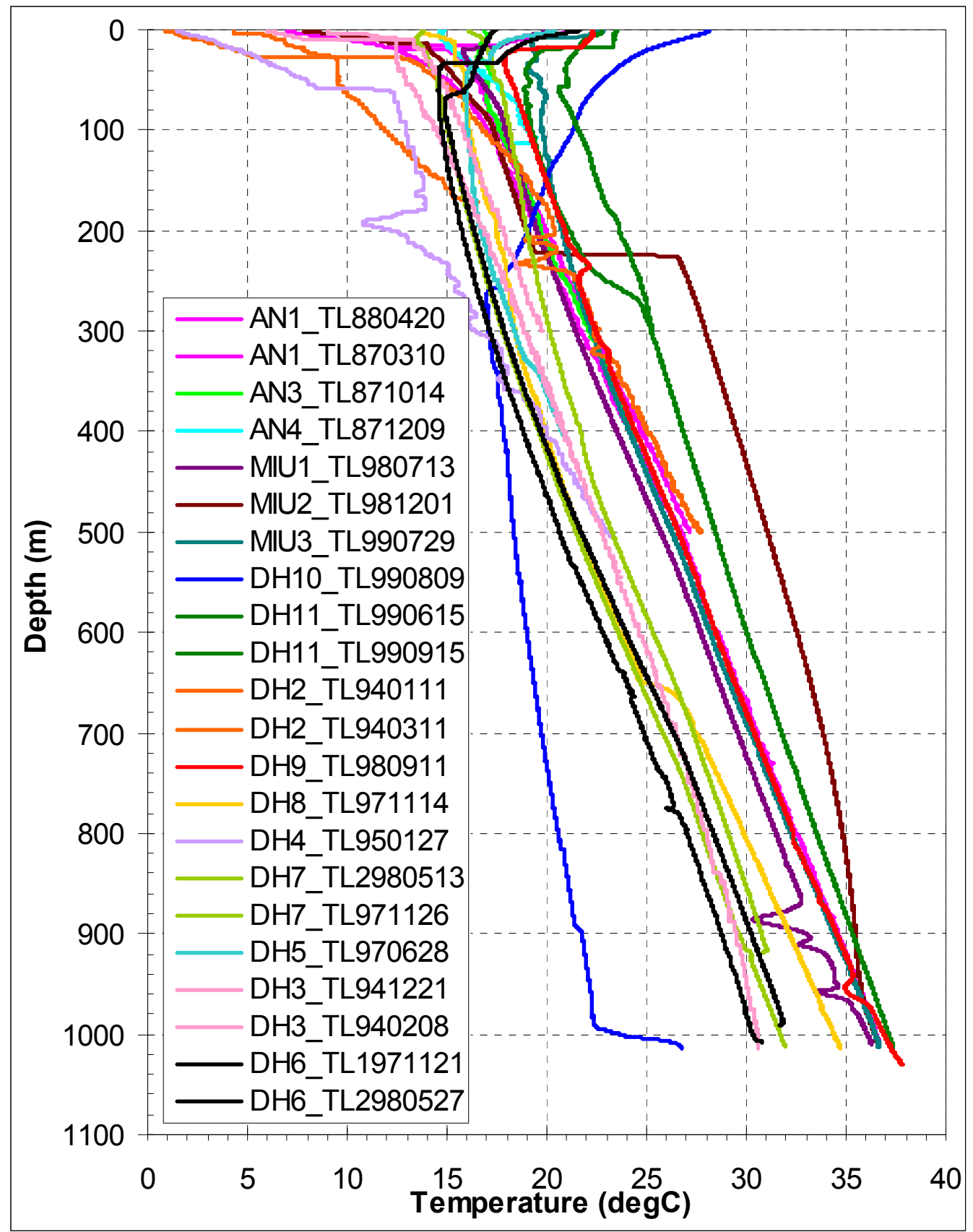

Figure 6.1. Borehole temperature profiles. Profiles measured in the same borehole at different times are shown in the same color. 


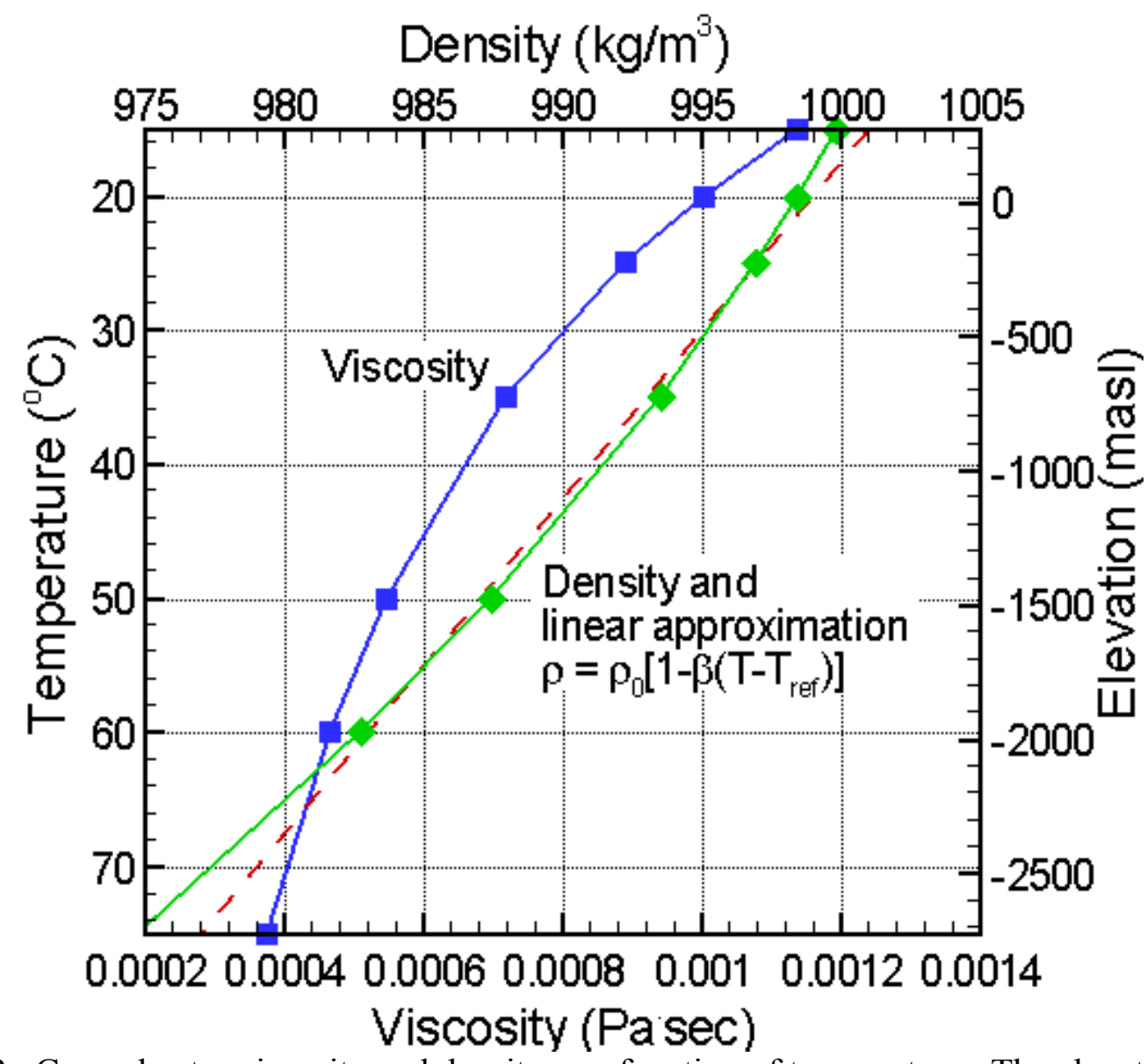

Figure 6.2. Groundwater viscosity and density as a function of temperature. The elevations shown on the right $y$-axis are calculated from temperature assuming a surface temperature of $15^{\circ} \mathrm{C}$ and a temperature gradient of $2^{\circ} \mathrm{C}$ per $100 \mathrm{~m}$. The linear density approximation is used for calculating the Rayleigh number (Equation (6.3)). 


\section{Uncoupled flow and temperature}

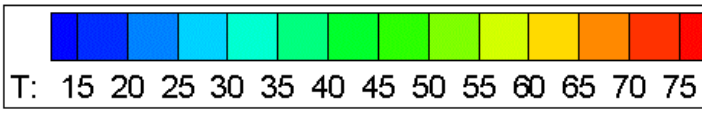

$\mathrm{x}=5589 \mathrm{~m}$

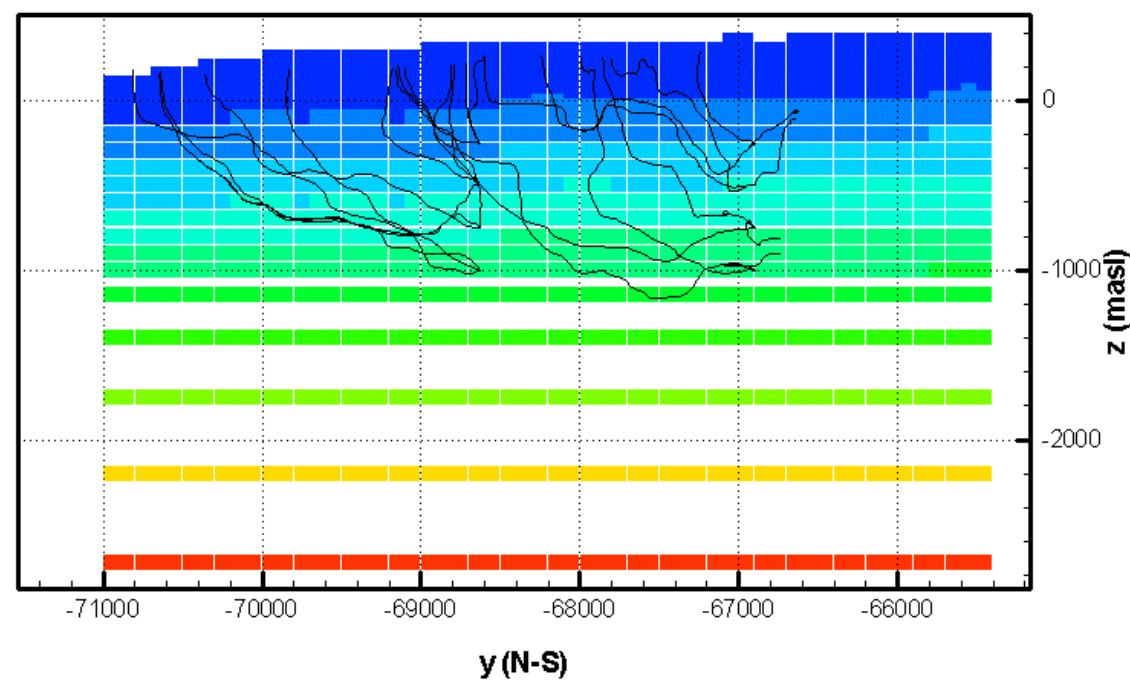

Figure 6.3. All stream traces leaving the 24 release points projected onto a vertical cross-section near the center of the model, for the new base case - open model, realization 1 . The fixed, nonuniform temperature distribution on the cross-section is also shown.

\section{Uncoupled flow and temperature}
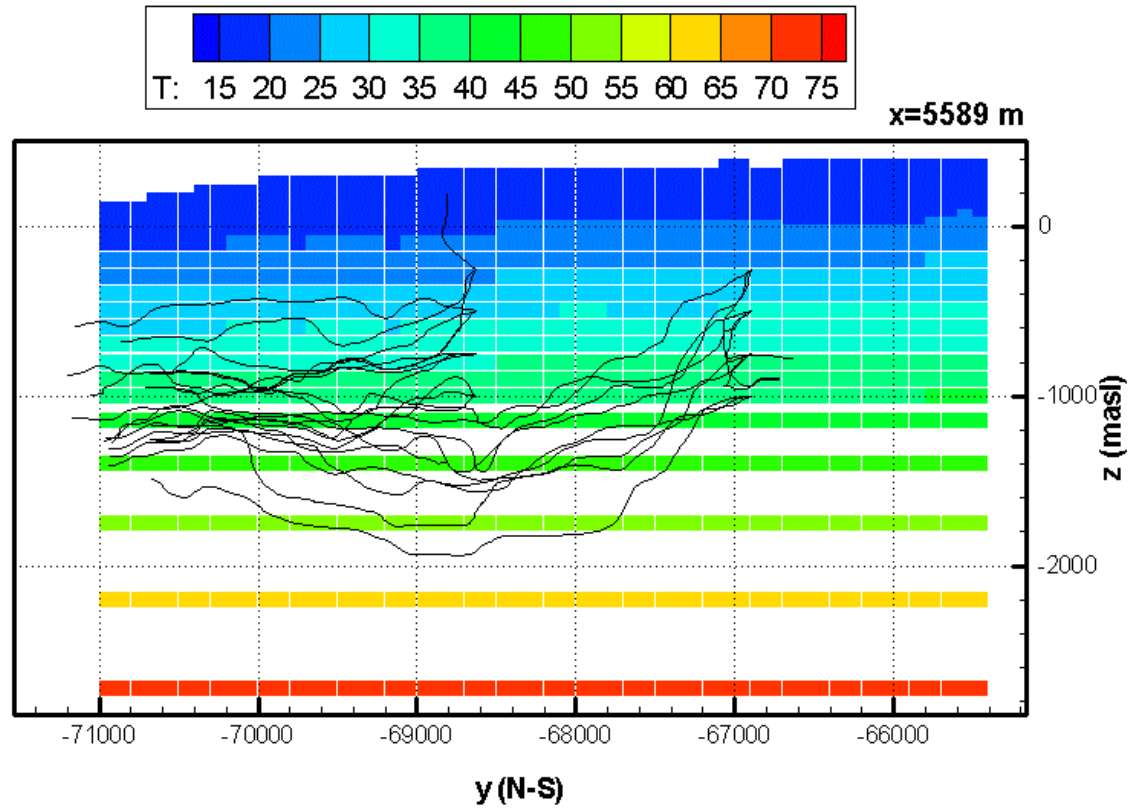

Figure 6.4. All stream traces leaving the 24 release points projected onto a vertical cross-section near the center of the model, for the new base case - closed model, realization 1 . The fixed, nonuniform temperature distribution on the cross-section is also shown. 
(a)

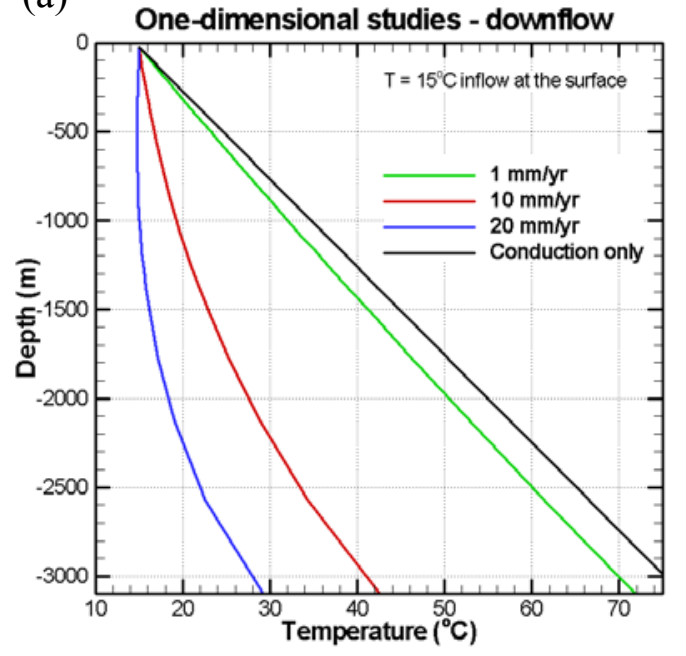

(c)

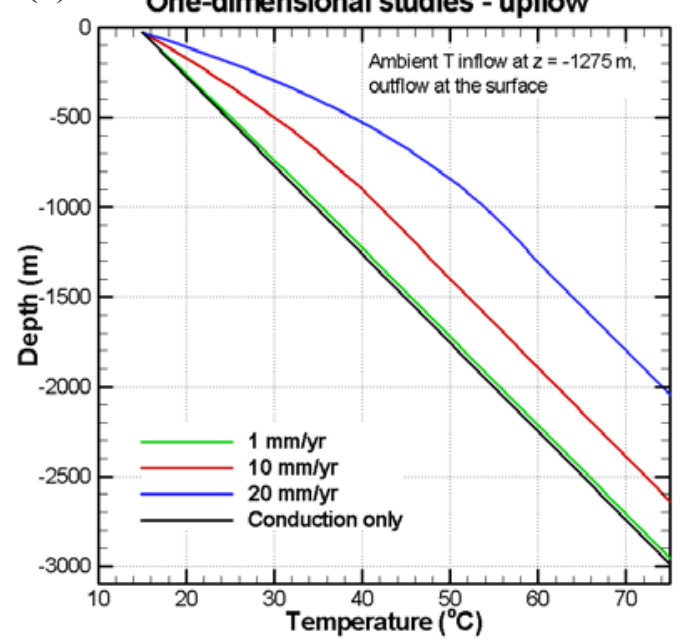

(b)

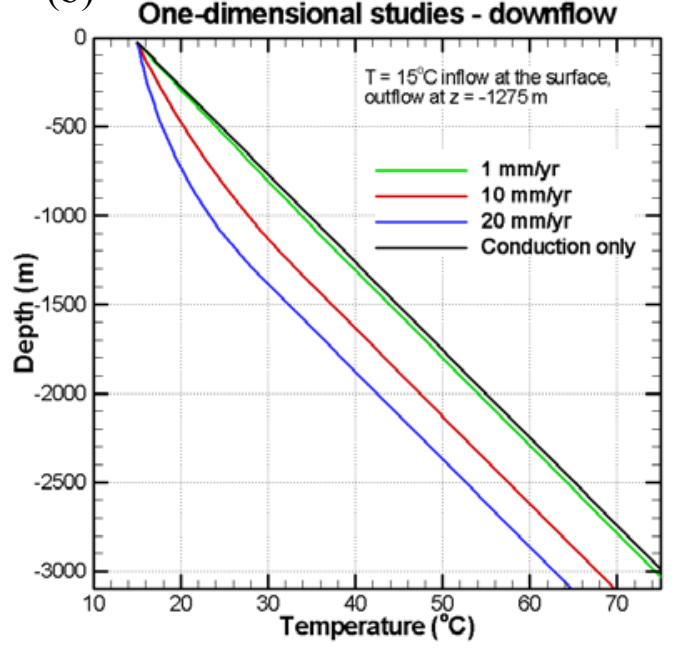

(d)

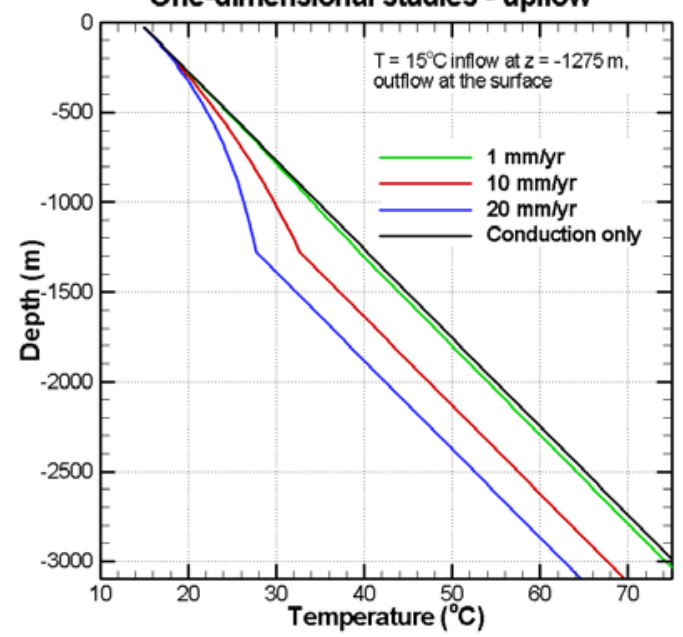

Figure 6.5. 1-D column models showing various scenarios combining convection and conduction. 

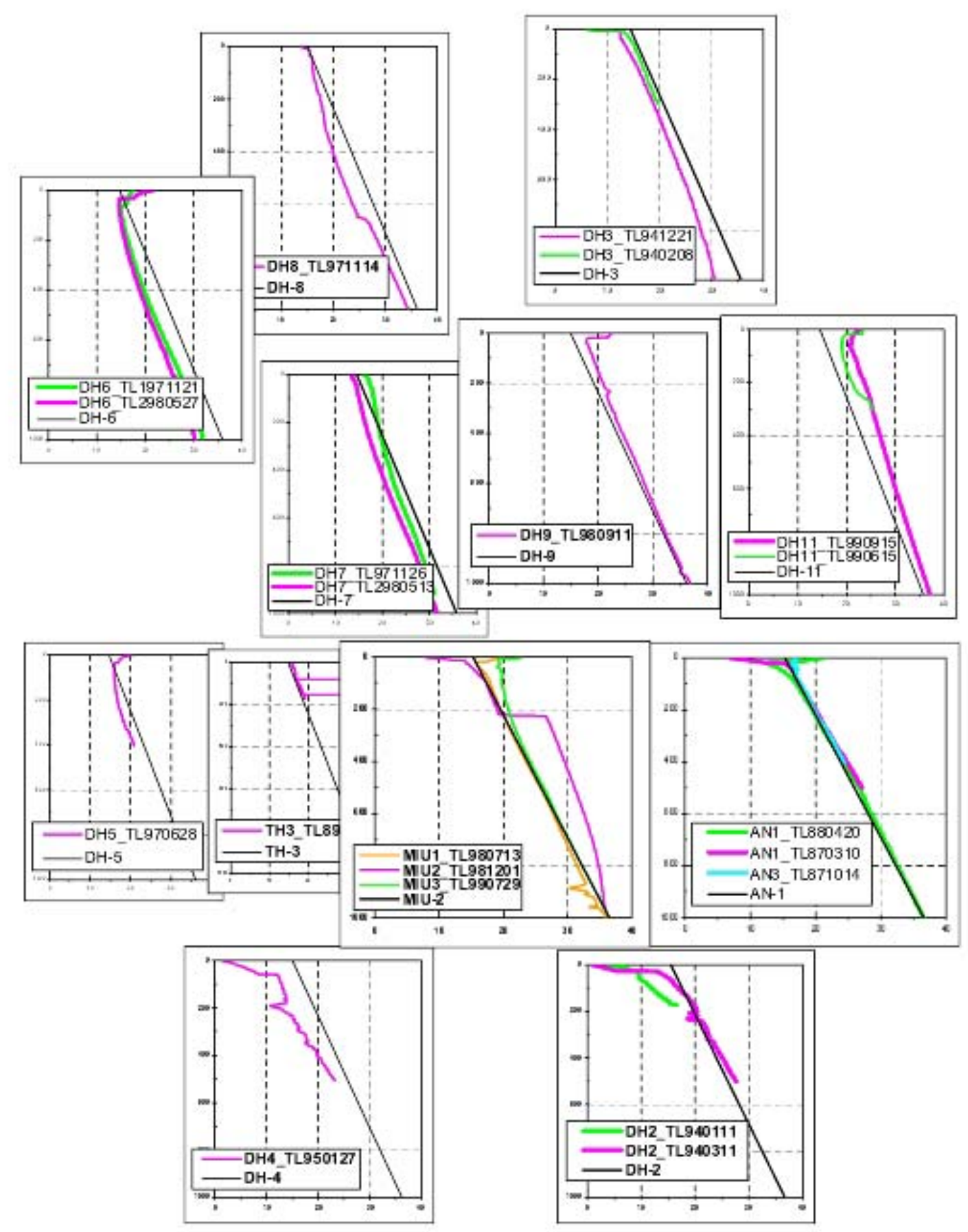

Figure 6.6. Observed temperature profiles. Plot location on the page is meant to roughly mimic well location in space. A conductive profile representing $2^{\circ} \mathrm{C}$ per $100 \mathrm{~m}$ is shown for reference on each plot. 


\section{Coupled flow and temperature}
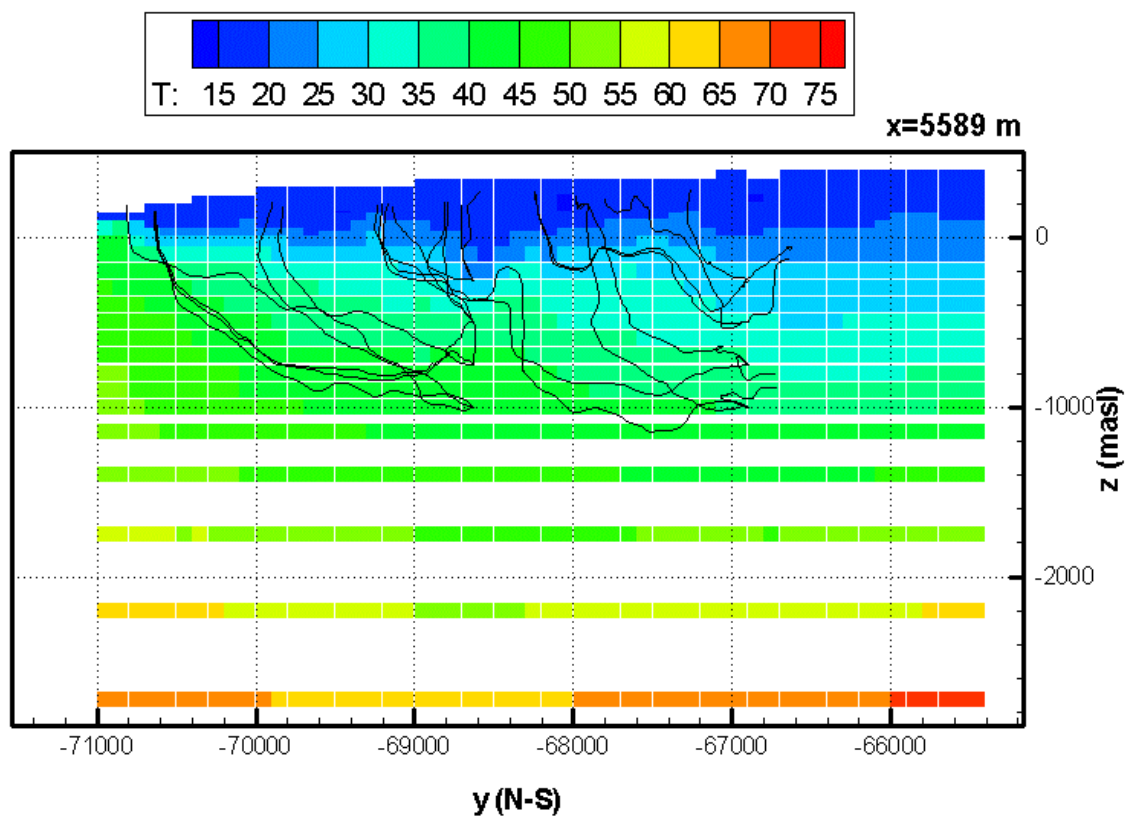

Figure 6.7. All stream traces leaving the 24 release points projected onto a vertical cross-section near the center of the model, for the new base case - open model, realization 1. The steady-state temperature distribution on the cross-section is also shown.

\section{Coupled flow and temperature}

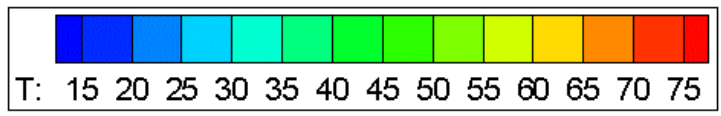

$$
\mathrm{x}=5589 \mathrm{~m}
$$

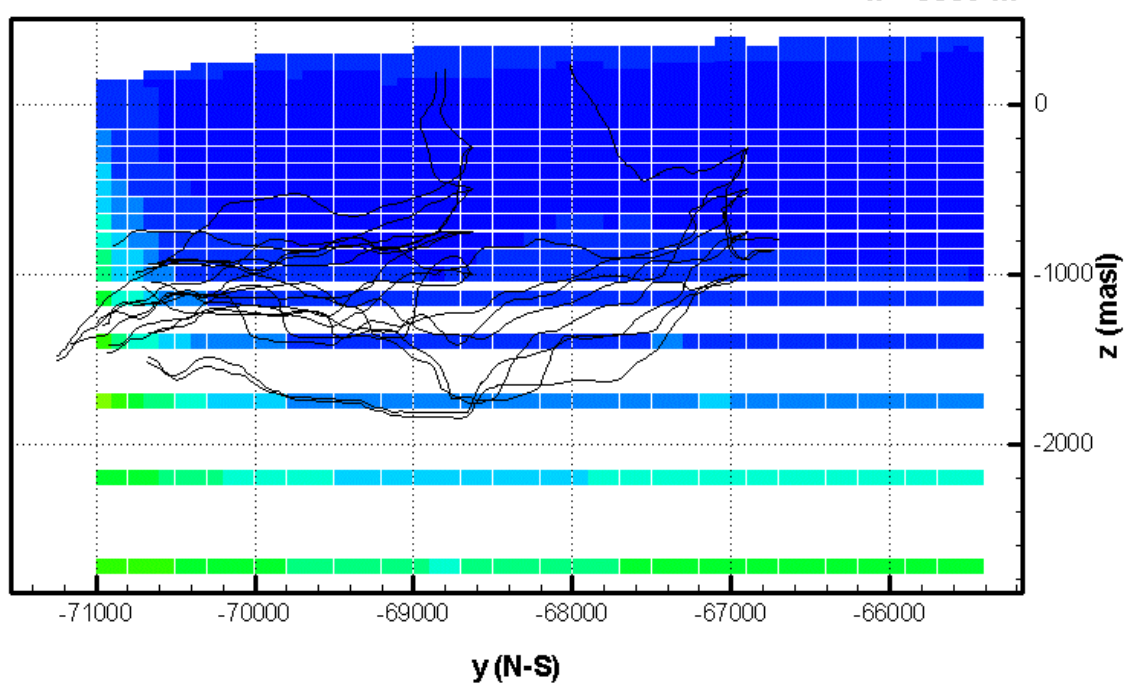

Figure 6.8. All stream traces leaving the 24 release points projected onto a vertical cross-section near the center of the model, for the new base case - closed model, realization 1. The steadystate temperature distribution on the cross-section is also shown. 

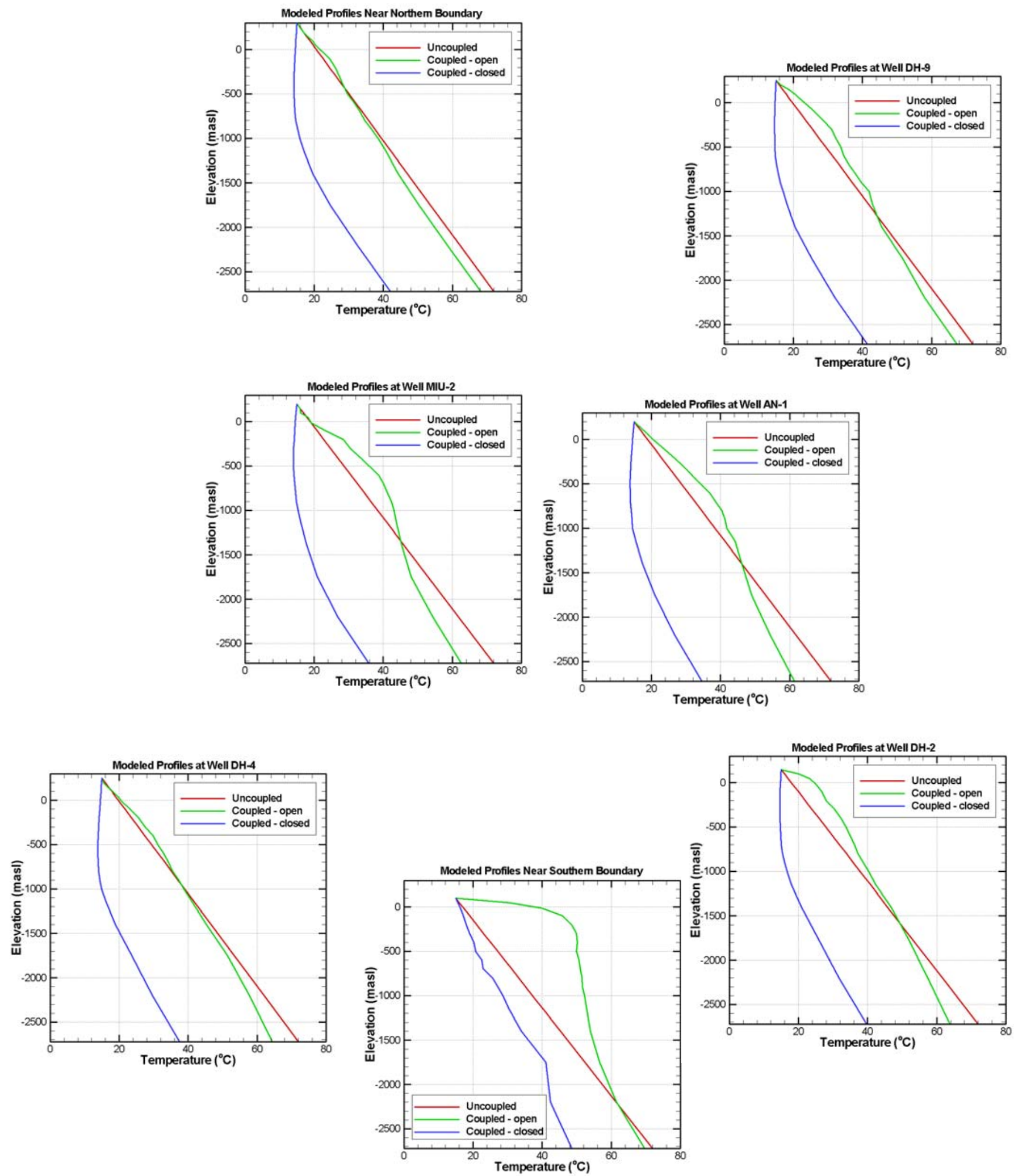

Figure 6.9. T vs. $z$ profiles extracted from the 3-D models. Plot location on the page is meant to roughly mimic well location in space. 